\title{
Next Generation Nuclear Plant Intermediate Heat Exchanger Acquisition Strategy
}

R. E. Mizia

April 2008

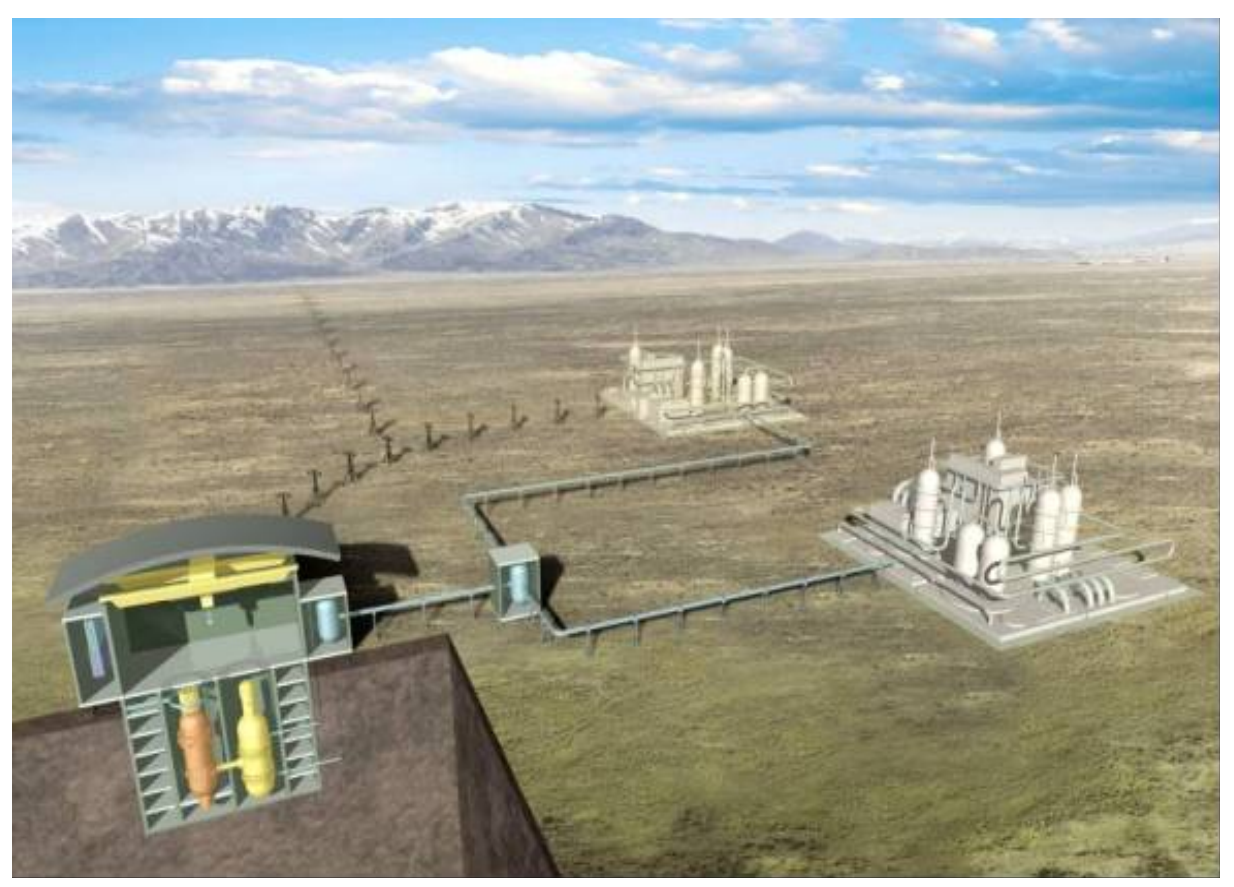




\section{DISCLAIMER}

This information was prepared as an account of work sponsored by an agency of the U.S. Government. Neither the U.S. Government nor any agency thereof, nor any of their employees, makes any warranty, expressed or implied, or assumes any legal liability or responsibility for the accuracy, completeness, or usefulness, of any information, apparatus, product, or process disclosed, or represents that its use would not infringe privately owned rights. References herein to any specific commercial product, process, or service by trade name, trade mark, manufacturer, or otherwise, does not necessarily constitute or imply its endorsement, recommendation, or favoring by the U.S. Government or any agency thereof. The views and opinions of authors expressed herein do not necessarily state or reflect those of the U.S. Government or any agency thereof. 
INL/EXT-08-14054

Revision 0

\title{
Next Generation Nuclear Plant Intermediate Heat Exchanger Acquisition Strategy
}

\author{
R. E. Mizia
}

April 2008

Idaho National Laboratory Idaho Falls, ID 83415

Prepared for the

U.S. Department of Energy

Assistant Secretary for the Office of Nuclear Energy

Under DOE Idaho Operations Office

Contract DE-AC07-05ID14517 


\title{
Next Generation Nuclear Plant Intermediate Heat Exchanger Acquisition Strategy
}

\author{
INL/EXT-08-14054
}

Revision 0

April 2008

Reviewed by:

R.N.Wright

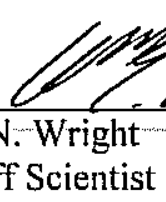

Approved by:

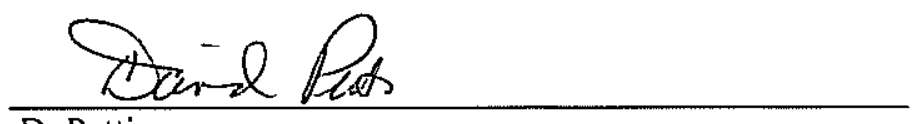

D. Petti

VHTR TDO Director

$\frac{4 / 30 / 08}{\text { Date }}$





\section{EXECUTIVE SUMMARY}

DOE has selected the High Temperature Gas-cooled Reactor (HTGR) design for the Next Generation Nuclear Plant (NGNP) Project. The NGNP will demonstrate the use of nuclear power for electricity and hydrogen production. It will have an outlet gas temperature in the range of 850 to $950^{\circ} \mathrm{C}$ and a plant design service life of 60 years. The reactor design will be a graphite moderated, helium-cooled, prismatic or pebble-bed reactor, and use low-enriched uranium, TRISO-coated fuel. The plant size, reactor thermal power, and core configuration will ensure passive decay heat removal without fuel damage or radioactive material releases during accidents. The NGNP Materials Research and Development (R\&D) Program is responsible for performing R\&D on likely NGNP materials in support of the NGNP design, licensing, and construction activities.

Selection of the technology and design configuration for the NGNP must consider both the cost and risk profiles to ensure that the demonstration plant establishes a sound foundation for future commercial deployments. The NGNP challenge is to achieve a significant advancement in nuclear technology while at the same time setting the stage for an economically viable deployment of the new technology in the commercial sector soon after 2020.

The purpose of this report is to address the acquisition strategy for the NGNP Intermediate Heat Exchanger (IHX). This component will be operated in flowing, impure helium on the primary and secondary side at temperatures up to $950^{\circ} \mathrm{C}$. There are major high temperature design, materials availability, and fabrication issues that need to be addressed. The prospective materials are Alloys 617, 230, $800 \mathrm{H}$ and XR, with Alloy 617 being the leading candidate for the use at $950^{\circ} \mathrm{C}$. The material delivery schedule for these materials does not pose a problem for a 2021 start up as the vendors can quote reasonable delivery times at the moment. The product forms and amount needed must be finalized as soon as possible.

An issue for the fabrication of the IHX pressure and tubular design heat exchanger is the identification of vessel fabrication vendors with the appropriate ASME certifications to perform nuclear work. The number of these firms has declined over the last 20 years and the NGNP will be competing for these services with resurgent orders for Light Water Reactors and chemical process facility components in a world market.

The proposed designs for the IHX include a plate machined heat exchanger (PMHE), plate fin heat exchanger (PFHE), and the plate stamped heat exchanger (PSHE) which are compact heat exchanger designs. The tubular IHX is a standard industrial design. Additional designs discussed in this report include the foam, capillary, and ceramic IHX designs, all of which are less mature technologies.

Based on this assessment, the following items are recommended:

- The final design of the IHX and other Heat Transport System (HTS) components needs to be completed before a procurement schedule that incorporates acquisition of materials of construction and component fabrication can be finalized and inserted into the overall NGNP schedule. A tubular type IHX design represents the minimum technical and schedule risk. 
- The present compact heat exchanger designs focus on Heatric, Inc. as the supplier. They use a diffusion bonding technique to join the channeled plates that form the core. More information is required on the mechanical properties of this joining technique for the preferred metallic material, Alloy 617. Other compact heat exchanger suppliers such as Velocys should be investigated. Diffusion bonding will remain a potential issue with this design.

- To insure that the metallic alloy materials such as Alloy 617 for the IHX and HTS are available in a timely manner, a program to buy intermediate product forms such as slab should be investigated. This would take the alloy fabrication process through the initial melting and secondary refining steps where the product availability would not have to depend on the melt shop schedule. This intermediate product form could be stored at the supplier's facility and could be made into the final products on an as-requested basis by the component fabricators.

- The NGNP Program should continue interaction with fabrication vendors as the IHX design matures. Of key importance is the development of detailed fabrication schedule information for the overall project schedule and execution of the required $R \& D$ and activities needed for the final procurement. 


\section{CONTENTS}

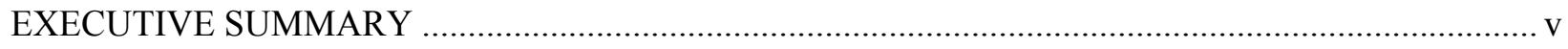

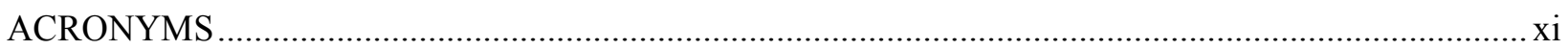

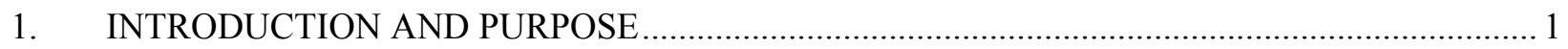

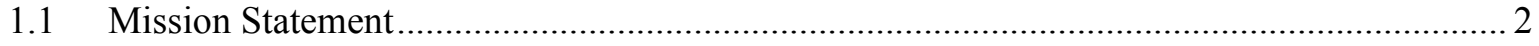

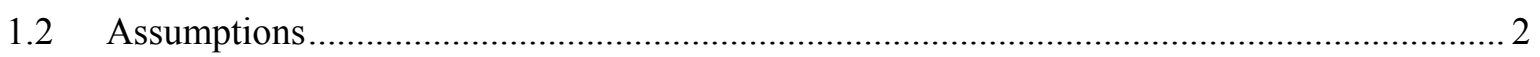

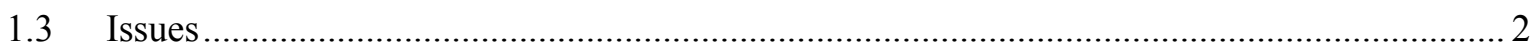

1.4 NGNP Reactor Vendors (Pre-Conceptual Design Phase) .................................................... 3

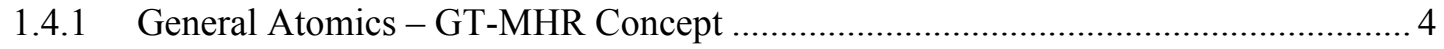

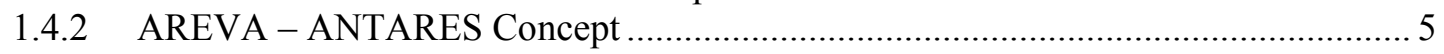

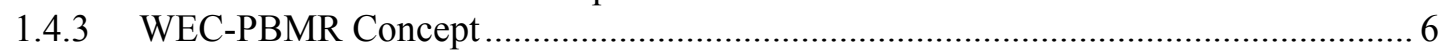

2. NGNP REACTOR VENDORS ADDITIONAL STUDIES (FY 2008) ......................................... 7

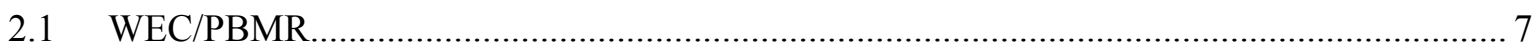

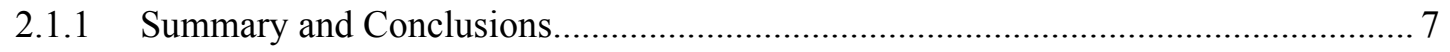

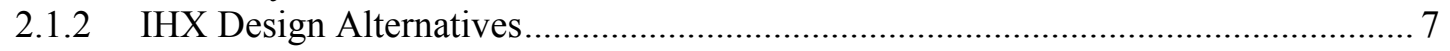

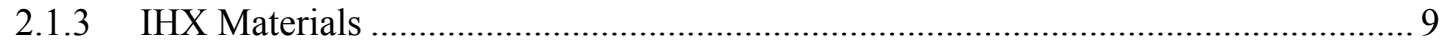

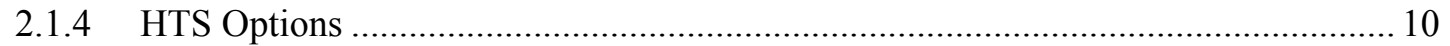

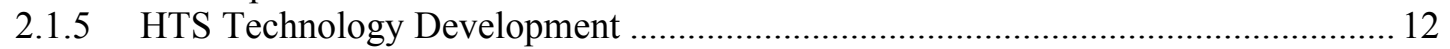

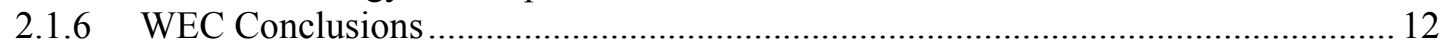

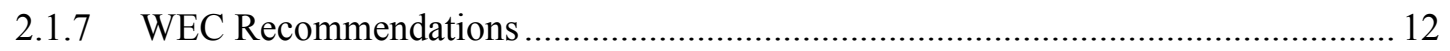

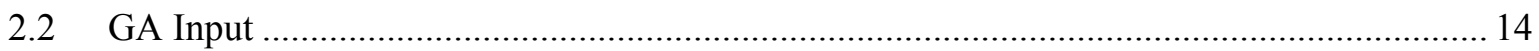

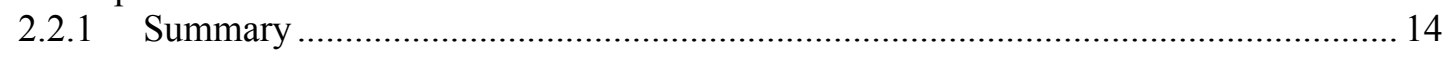

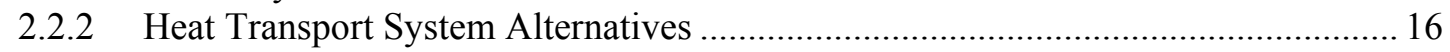

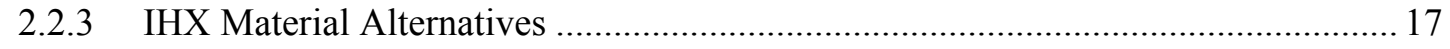

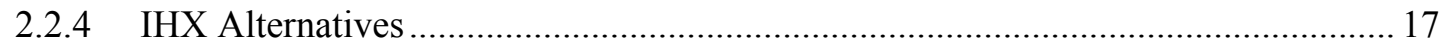

2.2.5 Helium Circulator Technology …................................................................ 18

2.2.6 Review of NRC Guidance and Regulations Potentially Applicable to NGNP ......... 19

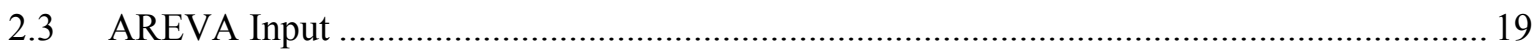

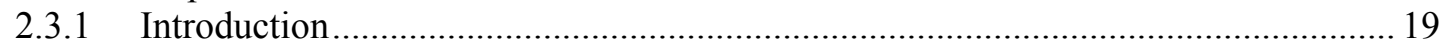

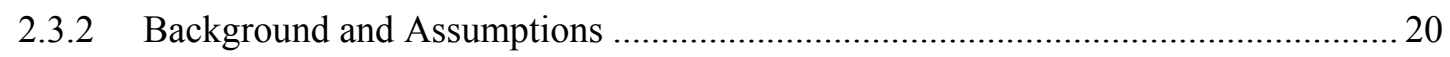

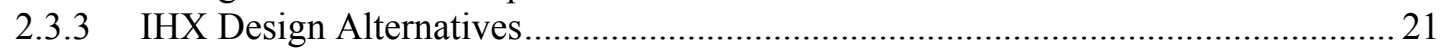

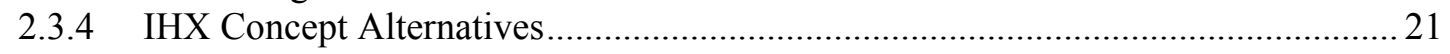

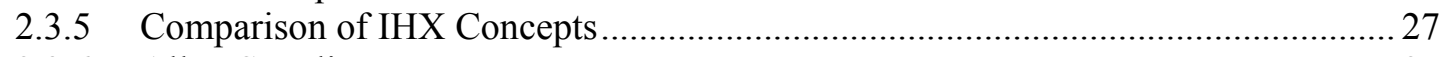

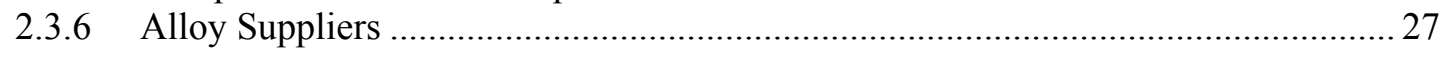

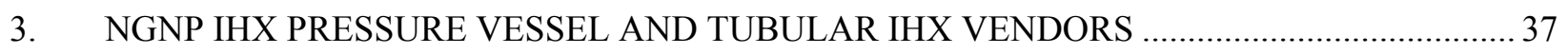

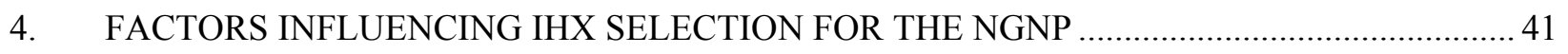

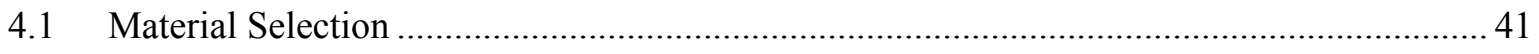

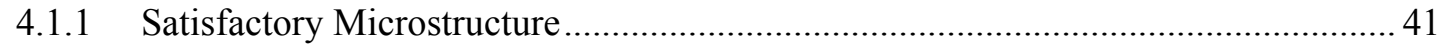

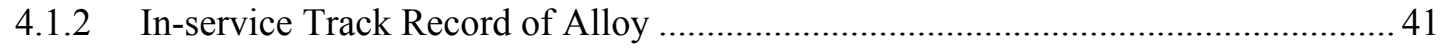

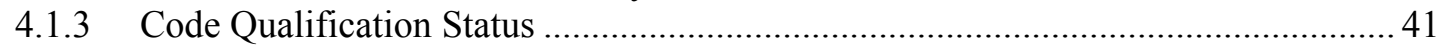

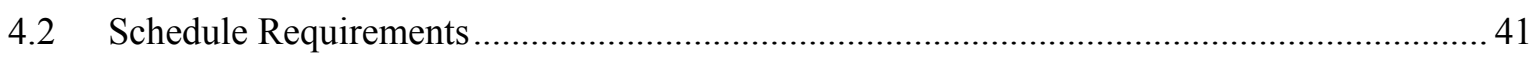

4.2.1 Material Research Needs ............................................................................. 41 


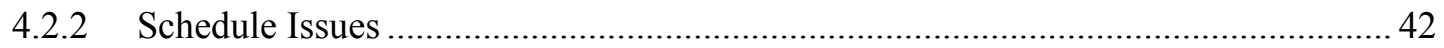

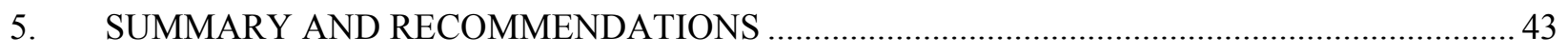

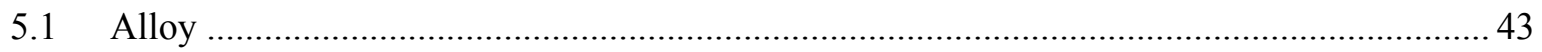

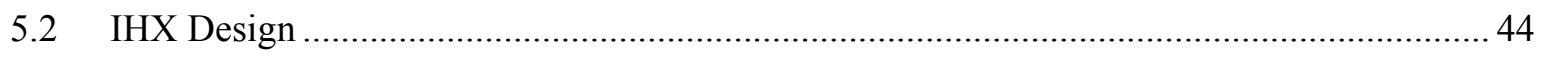

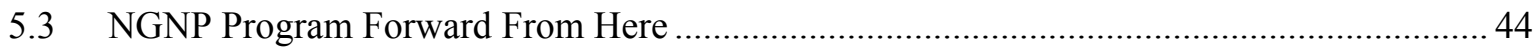

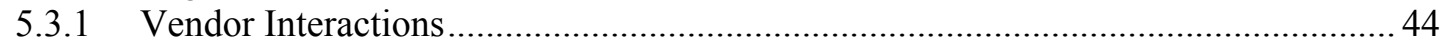

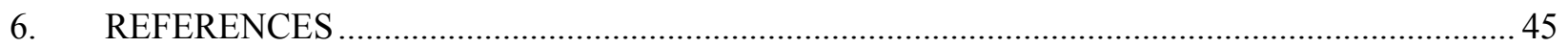




\section{FIGURES}

Figure 2-1. Core-side and shell-side PHTS coupling options................................................................ 8

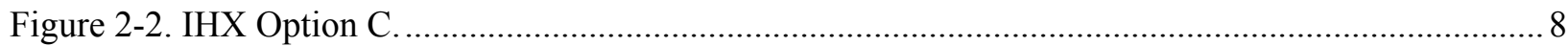

Figure 2-3. NGNP heat transport configuration - serial arrangement. .................................................. 15

Figure 2-4. NGNP heat transport configuration - parallel primary loop arrangement........................... 15

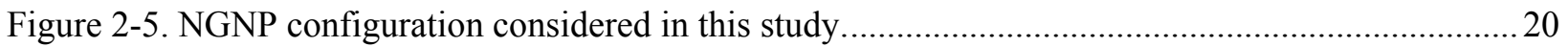

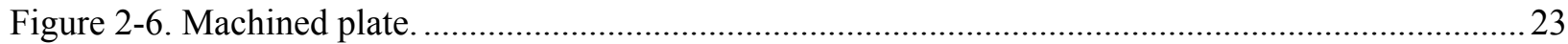

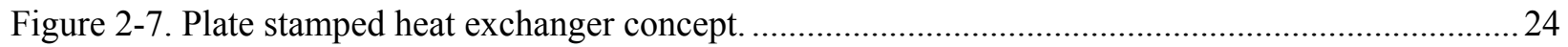

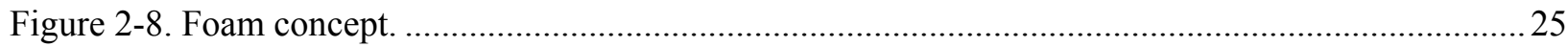

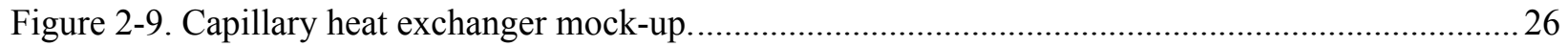

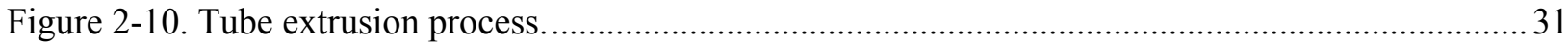

TABLES

Table 1-1. Key operating parameters for the NGNP designs and the Fort St. Vrain HTGR...................... 4

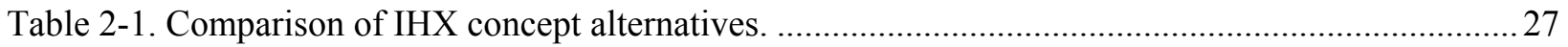

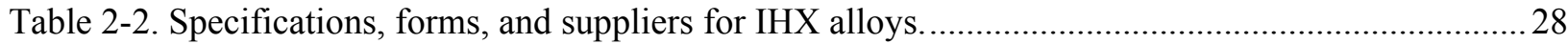

Table 3-1 IHX pressure vessel and tubular heat exchanger fabrication vendors. ..................................... 38

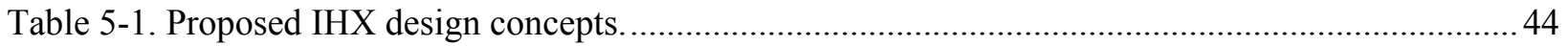




\section{ACRONYMS}

ASME American Society of Mechanical Engineers

AVR Arbeitsgemeinschaft Versuchsreaktor

CCGT Combined Cycle Gas Turbine

CHE Capillary Heat Exchanger

CV Cross Vessel

DBE Design Basis Event

DDN Design Data Need

DHI Doosan Heavy Industries and Construction

DID Defense-in-Depth Principle

DOE Department of Energy

FSV Fort St. Vrain

GA General Atomics

GT-MHR Gas Turbine Modular Helium Reactor

HPS Hydrogen Production System

HT Heat Transfer

HTGR High Temperature Gas-cooled Reactor

HTR High-Temperature Reactor

HTS Heat Transport System

HTTR High-Temperature Engineering Test Reactor

IHX Intermediate Heat Exchanger

INL Idaho National Laboratory

ISI In-Service Inspection

JAERI Japan Atomic Energy Research Institute

KAERI Korean Atomic Energy Research Institute

KVK Komponentenversuchs $\underline{k}$ reislauf (Component Test Facility)

LMTD Long Mean Temperature Difference

LOSP Loss of Secondary Pressure

LWR Light Water Reactor

MHR Modular Helium Reactor

NGNP Next Generation Nuclear Plant

NHS Nuclear Heat Source

NHSS Nuclear Heat Steam System

NRC Nuclear Regulatory Commission

ORNL Oak Ridge National Laboratory

PBMR Pebble Bed Modular Reactor

PCDSR Preconceptual Design Studies Report

PCHE Printed Circuit Heat Exchanger

PCS Power Conversion System

PCU Power Conversion Unit

PFHE Plate-Fin Heat Exchanger

PHTS Primary Heat Transport System

PMHE Plate Machined Heat Exchanger

PMR Prismatic Modular Reactor 
PNP Process Nuclear Heat Plant

PSHE Plate Stamped Heat Exchanger

PWR Pressurized Water Reactor

QA Quality Assurance

R\&D Research and Development

RPV Reactor Pressure Vessel

SHTS Secondary Heat Transport System

SSC Structures, Systems, and Components

THTR Thorium Hochtemperatur Reaktor

TRISO Tri-Isotopic

URS-WD URS - Washington Division

VHTR Very High Temperature Reactor 


\section{Next Generation Nuclear Plant Intermediate Heat Exchanger Acquisition Strategy}

\section{INTRODUCTION AND PURPOSE}

The Department of Energy (DOE) has selected the High Temperature Gas-cooled Reactor (HTGR) design for the Next Generation Nuclear Plant (NGNP) Project. The NGNP will demonstrate the use of nuclear power for electricity and hydrogen production. The reactor design will be a graphite moderated, helium-cooled, prismatic or pebble-bed, thermal neutron spectrum reactor. The NGNP will use very high burn-up, low-enriched uranium, Tri-Isotopic (TRISO)-coated fuel and have a projected plant design service life of 60 years. The HTGR concept is considered to be the nearest-term reactor design that has the capability to efficiently produce hydrogen. The plant size, reactor thermal power, and core configuration will ensure passive decay heat removal without fuel damage or radioactive material releases during accidents.

The basic technology for the NGNP was established in former high-temperature gas-cooled reactor plants (e.g., DRAGON, Peach Bottom, Albeitsgemeinschaft Versuchsreaktor [AVR], Thorium Hochtemperatur Reaktor [THTR], and Fort St. Vrain [FSV]). These reactor designs represent two design categories: the Pebble Bed Reactor and the Prismatic Modular Reactor (PMR). Commercial examples of potential NGNP candidates are the Gas Turbine-Modular Helium Reactor (GT-MHR) from General Atomics (GA), the High Temperature Reactor concept (ANTARES) from AREVA, and the Pebble Bed Modular Reactor (PBMR) from the PBMR consortium. Furthermore, the Japanese High-Temperature Engineering Test Reactor (HTTR) and the Chinese High-Temperature Reactor (HTR) are demonstrating the feasibility of the reactor components and materials needed for NGNP. (The HTTR reached a maximum coolant outlet temperature of $950^{\circ} \mathrm{C}$ in April 2004.) Therefore, the NGNP is focused on building a demonstration plant, rather than simply confirming the basic feasibility of the concept.

The operating conditions for the NGNP represent a major departure from existing water-cooled reactor technologies. Few choices exist for metallic alloys for use at NGNP conditions and the design lifetime considerations for the metallic components may restrict the maximum operating temperature. Qualification of materials for successful and long-life application at the high-temperature conditions planned for the NGNP is a large portion of the effort in the NGNP Materials Research and Development (R\&D) Program.

Selection of the technology and design configuration for the NGNP must consider both the cost and risk profiles to ensure that the demonstration plant establishes a sound foundation for future commercial deployments. The NGNP challenge is to achieve a significant advancement in nuclear technology while at the same time setting the stage for an economically viable deployment of the new technology in the commercial sector soon after 2020.

A major component of the NGNP is the Intermediate Heat Exchanger (IHX). This component will transfer heat to secondary systems that will generate electricity or hydrogen. The IHX will be operated in flowing, impure helium on the primary and secondary side at temperatures up to $950^{\circ} \mathrm{C}$. There are major high temperature design, materials availability, and fabrication issues that need to be addressed. The prospective materials are Alloys 617, 230, 800H and XR with Alloy 617 being the leading candidate for use at $950^{\circ} \mathrm{C}$. 


\subsection{Mission Statement}

Developing this acquisition strategy is part of the NGNP Materials Research and Development (R\&D) Program. The objective of the NGNP Materials R\&D Program is to provide the essential materials studies and laboratory investigations needed to support the design and licensing of the reactor and balance of plant, excluding the hydrogen plant. The materials R\&D program was initiated prior to the design effort to ensure that materials R\&D activities are initiated early enough to support the design process. The thermal, environmental, and service life conditions of the NGNP will make selection and qualification of the high-temperature materials a significant challenge; thus, new materials and approaches may be required. The mission of the NGNP Materials Program must support the objectives associated with the NGNP in the Energy Policy Act of 2005 and provide any materials related support required during the development of the NGNP.

\subsection{Assumptions}

The following assumptions are given for this task:

- The NGNP will be a full-sized reactor plant capable of electricity generation with a hydrogen demonstration unit of appropriate size.

- The reactor design will be a helium-cooled, graphite moderated core design fueled with TRISOdesign fuel particles in carbon-based compacts or pebbles.

- $\quad$ The NGNP must demonstrate the capability to obtain a Nuclear Regulatory Commission (NRC) operating license. The design, materials, and construction will need to meet appropriate Quality Assurance (QA) methods and criteria and other nationally recognized codes and standards.

- The demonstration plant will be designed to operate for a nominal 60 years.

- The NGNP Program including the materials program will continue to be directed by the Idaho National Laboratory (INL) based on the guidelines given in the Energy Policy Act of 2005. The scope of work will be adjusted to reflect the level of congressional appropriations.

- Application for an NRC operating license and fabrication of the NGNP will occur with direct interaction and involvement of one or more commercial organizations.

\subsection{Issues}

The last HTGR design reactor built in the US was the FSV reactor which was constructed in the early 1970's, generated the first power sent to the grid in 1976, and was taken out of service in 1989. The fact that there has been no HTGR construction in this country since then along with the long gap in construction of Light Water Reactors (LWRs) puts the NGNP in the situation where there is a lack of current industry technical information and experience with regard to the materials of construction and fabrication practices associated with the NGNP designs currently under consideration.

The design effort needs to be completed which will include a final IHX design so a material acquisition list can be developed. There needs to be new information developed as regards the primary metals producers who can produce the high temperature alloys in the required product forms specified for use in the IHX. For compact IHX designs joining and inspection R\&D will be necessary.

Another issue will be the identification of vessel fabrication vendors with the appropriate American Society of Mechanical Engineers (ASME) certifications to perform nuclear work. The number of these firms has declined over the last 20 years and the NGNP will be competing for these services with resurgent orders for LWR's and chemical process facility components in a world market. There is significant competition for these fabrication resources. 
To meet the NGNP startup date of 2021, these IHX must be delivered much earlier. The needed delivery date must be identified and a schedule for material acquisition and fabrication must be developed. For a given desired delivery date the following steps need to be completed with the appropriate completion dates:

1. Place material order with primary metal producer to obtain position in the melting schedule to secure material for fabrication.

2. Finalize material shapes and sizes (tubing, sheet, forgings, plate) and choose the appropriate specifications for the intermediate product mill.

3. Secure fabrication vendor services and ship material to his facility.

4. Completion date for fabrication.

5. Shipment to Idaho.

6. Installation of the IHX and other major equipment to meet start up schedule.

\subsection{NGNP Reactor Vendors (Pre-Conceptual Design Phase)}

The HTGR is an inherently safe nuclear reactor concept with a safety basis that has the potential to substantially reduce emergency planning requirements and improved siting flexibility compared to current and advanced light water reactors. The viability of a graphite core planned for the NGNP has previously been demonstrated in former high-temperature gas-cooled reactor plants (e.g., DRAGON, Peach Bottom, AVR, THTR, and FSV). Furthermore, the Japanese High-Temperature Engineering Test Reactor (HTTR) and Chinese High-Temperature Reactor (HTR) are currently operating and contributing to demonstrating the feasibility of the reactor components and materials needed for NGNP (HTTR reached a maximum coolant outlet temperature of $950^{\circ} \mathrm{C}$ in April 2004). These reactor designs represent two categories: the Pebble Bed Reactor (PBR) and the Prismatic Modular Reactor (PMR), respectively.

This section describes the current HTGR pre-conceptual designs in summary form which are described in detail in the NGNP Pre-Conceptual Design Report. ${ }^{1}$ In FY-07 this pre-conceptual design work was initiated by the NGNP Project at the INL. This work was completed by three contractor teams with extensive experience in HTGR technology, nuclear power applications and hydrogen production. Each contractor developed a recommended design for NGNP and a commercial version of the HTGR. $R \& D$, data needs, and future studies required to achieve operation of the NGNP were identified as part of the work. In addition, a number of special studies were requested from all three or two of the three teams. The special studies include Reactor Type Trade Study, ${ }^{2}$ Pre-conceptual Heat Transfer and Transport Studies, ${ }^{3}$ Primary and Secondary Cycle Trade Study, ${ }^{4}$ and Power Conversion System Trade Study. ${ }^{5}$ The three designs developed are as follows:

1. The GT-MHR concept; team led by General Atomics (GA) teamed with; Washington Group International; Rolls-Royce (United Kingdom); Toshiba Corporation and Fuji Electric Systems (Japan); Korean Atomic Energy Research Institute (KAERI), and OKB Mechanical Design (Russia).

2. The ANTARES concept; team led by AREVA NP, Inc. teamed with; Burns \& Roe; Washington Group International, BWXT, Dominion Engineering, Air Products, Hamilton-SundstrandRocketdyne, Mitsubishi Heavy Industries, Nova Tech, and Entergy.

3. The PBMR concept; team led by Westinghouse Electric Company, LLC teamed with; Pebble Bed Modular Reactor (Pty) Ltd. and M-Tech Industrial (Pty) Ltd. (South Africa); The Shaw Group; Technology Insights; Air Products and Chemicals, Inc.; Nuclear Fuel Services; and Kadak Associates. 
All three designs utilize TRISO fuel, graphite moderation and high temperature helium coolant in the primary system in the $800-950^{\circ} \mathrm{C}$ temperature range. All of the concepts feature various passive neutronic design features which result in a core with relatively low power density and a negative temperature coefficient of neutron reactivity. The shut-down cooling system, the secondary reactivity shut-down system, and the control rod design are all similar among the three designs. All of the reactor concepts could be used as a basis for the NGNP HTGR. Although the designs will not be presented in detail here, the features that relate to IHX material selection and challenges will be discussed. The key operating parameters and design features for all three designs are listed in Table 1-1 along with information for the FSV HTGR, the largest and most recent gas-cooled reactor to operate in the US.

Table 1-1. Key operating parameters for the NGNP designs and the Fort St. Vrain HTGR.

\begin{tabular}{|c|c|c|c|c|}
\hline Condition or Feature & $\begin{array}{l}\text { Fort St. Vrain } \\
\text { (FSV) HTGR }\end{array}$ & $\begin{array}{c}\text { General Atomics } \\
\text { GT-MHR }\end{array}$ & $\begin{array}{c}\text { AREVA } \\
\text { ANTARES }\end{array}$ & $\begin{array}{l}\text { Westinghouse } \\
\text { PBMR }\end{array}$ \\
\hline Power Output [MW(t)] & 842 & $550-600$ & 565 & 500 \\
\hline Average power density $\left(\mathrm{w} / \mathrm{cm}^{3}\right)$ & 6.3 & 6.5 & & 4.8 \\
\hline Moderator & Graphite & Graphite & Graphite & Graphite \\
\hline Core Geometry & Cylindrical & Annular & Annular & Annular \\
\hline Reactor type & Prismatic & Prismatic & Prismatic & Pebble Bed \\
\hline Safety Design Philosophy & Active & Passive & Passive & Passive \\
\hline Plant Design Life (Years) & 30 & 60 & 60 & 60 \\
\hline Fuel - Coated Particle & $\begin{array}{l}\text { HEU-Th } /{ }^{235} \mathrm{U} \\
\text { (93\% enriched) }\end{array}$ & $\begin{array}{l}\text { TRISO UCO } \\
\text { (startup } \mathrm{UO}_{2} \text { ) }\end{array}$ & $\begin{array}{l}\text { TRISO UCO } \\
\text { (backup } \mathrm{UO}_{2} \text { ) }\end{array}$ & TRISO $\mathrm{UO}_{2}$ \\
\hline $\begin{array}{l}\text { Fuel Max Temp - Normal } \\
\text { Operation }\left({ }^{\circ} \mathrm{C}\right)\end{array}$ & 1260 & 1250 & 1300 & 1057 \\
\hline $\begin{array}{l}\text { Fuel Max Temp - Emergency } \\
\text { Conditions }\left({ }^{\circ} \mathrm{C}\right)\end{array}$ & $\begin{array}{l}\text { NA - Active } \\
\text { Safety System } \\
\text { cools fuel. }\end{array}$ & 1600 & 1600 & 1600 \\
\hline $\begin{array}{l}\text { Power Conversion } \\
\text { Configuration }\end{array}$ & Direct & Direct & Indirect & Indirect \\
\hline $\begin{array}{l}\text { PCS Cycle Type } \\
\text { IHX Design Power }\end{array}$ & Reheat Steam & Brayton & $\begin{array}{l}\text { Steam Rankine } \\
\text { Shell \& Tube }\end{array}$ & Rankine \\
\hline Process & NA & PCHE & $\begin{array}{l}\text { PCHE or } \\
\text { Fin-Plate }\end{array}$ & PCHE \\
\hline Core outlet temperature $\left({ }^{\circ} \mathrm{C}\right)$ & 785 & Up to 950 & 900 & 950 \\
\hline Core inlet temperature $\left({ }^{\circ} \mathrm{C}\right)$ & 406 & 590 & 500 & 400 \\
\hline Coolant Pressure (MPa) & 4.8 & 7 & 5 & 9 \\
\hline Coolant Flow Rate $(\mathrm{kg} / \mathrm{s})$ & 428 & 320 & 240 & 193 \\
\hline $\begin{array}{l}\text { Secondary outlet temperature } \\
\left({ }^{\circ} \mathrm{C}\right)\end{array}$ & 538 & 925 & $\begin{array}{l}850 / 875 \\
\mathrm{PCS} / \mathrm{H}_{2}\end{array}$ & 900 \\
\hline $\begin{array}{l}\text { Secondary inlet temperature } \\
\left({ }^{\circ} \mathrm{C}\right)\end{array}$ & NA & 565 & $\begin{array}{l}450 / 475 \\
\mathrm{PCS} / \mathrm{H}_{2}\end{array}$ & NA \\
\hline Secondary Fluid & Steam & $\mathrm{He}$ & $\mathrm{He}$ & $\mathrm{He}-\mathrm{N}$ \\
\hline
\end{tabular}

\subsubsection{General Atomics - GT-MHR Concept}

General Atomics recommended a prismatic reactor design. The core consists of graphite blocks with an annular-fueled region of 1020 prismatic fuel blocks arranged in three columns. They argue that a prismatic reactor inherently allows higher reactor power density levels, resulting in better plant 
economics, involves fewer uncertainties (and therefore less risk) and allows more flexibility with respect to the use of alternate fuel cycles, such as those fabricated from surplus weapons grade plutonium or transuranics separated from spent LWR fuel. ${ }^{1,2}$ The temperature rise of the coolant in the various flow paths through the core varies over a wide range. Good mixing of the outlet coolant is needed to avoid excessive thermal stresses in the downstream components resulting from large temperature gradients and fluctuations, and to assure that the gas entering the turbine has a uniform mixed mean temperature.

General Atomics recommends the use of a direct Brayton Cycle vertical Power Conversion System (PCS) for electricity generation and an indirect heat transport loop to transport thermal energy to the hydrogen production plant. The primary loop and the hydrogen heat transport loop would both use helium at $7 \mathrm{MPa}$ as a heat transport medium.

\subsubsection{Intermediate Heat Exchanger}

Two alternative IHX designs were developed based on the printed circuit heat exchanger (PCHE) concept with one design developed by Heatric Corporation and the second design developed by Toshiba Corporation. These designs consist of metal plates that are diffusion bonded together with flow channels that are chemically milled into the plate. The PCHE concept allows for simultaneous high-temperature and high pressure operation with relatively thin wall thicknesses between the primary and secondary coolants. The PCHE designs are typically four to six times smaller than conventional shell-and tube heat exchangers of equivalent duty and designs have been developed with thermal effectiveness greater than $98 \%$.

An alternative design using a shell and tube, counter-flow heat exchanger using a helically coiled tube was developed by Toshiba Corporation. For an equivalent heat duty and long mean temperature difference (LMTD), this type of heat exchanger is considerably larger than a PCHE. This design allows for in-service inspection (ISI) of the heat transfer tubes. This design has successfully operated in the HTTR.

\subsubsection{AREVA - ANTARES Concept}

AREVA recommended that the NGNP be a $565 \mathrm{MWt}$ prismatic reactor, citing greater economic potential, higher power level and passive safety, more useable power, greater design flexibility, higher degree of license-ability (concept previously licensed for Fort St. Vrain), higher degree of predictability in core performance, forced outages and scheduled outages than a pebble bed reactor design. They suggest a gas outlet temperature of $900^{\circ} \mathrm{C}$ as the best compromise between energy efficiency and the ability to produce hydrogen, and the durability of equipment. AREVA proposes using $\mathrm{He} / \mathrm{N}_{2}$ mixture in the power conversion unit (PCU), and $900^{\circ} \mathrm{C}$ is the maximum temperature they advise for nitrogen bearing gas because of nitriding concerns. ${ }^{5}$ Use of the high nitrogen gas on the secondary side was specified because it simplifies technology development for the power turbine.

The ANTARES design ${ }^{6,7}$ is also based in part on the GT-MHR concept, with 1020 fuel blocks arranged in three columns to form the annular core between inner and outer graphite reflectors. The primary loop pressure is limited to $5.5 \mathrm{MPa}$ which is substantially less than the 7 to $9 \mathrm{MPa}$ specified by the other contractors.

AREVA provided two plant configurations - a plant configuration with a Brayton Cycle to generate electrical power, and a plant configuration with steam to generate electricity by using a Rankine Cycle. The Brayton Cycle configuration is based upon the original ANTARES design. AREVA has recently concluded that the Rankine Cycle is more mature and may be more adaptable to NGNP requirements, and therefore preferable. 


\subsubsection{Intermediate Heat Exchanger}

AREVA selected a compact He to He IHX for the heat transport loop to the hydrogen production plant. For the heat transfer to the electrical generation plant, AREVA selected a shell and tube heat exchanger.

\subsubsection{WEC-PBMR Concept}

This reactor is being developed in South Africa by PBMR (Pty) Ltd. through a world-wide development effort. ${ }^{8,9,10,11}$ The program includes testing of mechanical systems and components, a comprehensive fuel development effort and a testing and verification program to support the licensing process. A full-sized demonstration PBMR reactor will be built at the Koeberg nuclear reactor site (owned by Eskom, the South African national utility) near Capetown, South Africa. Westinghouse recommended a pebble-bed reactor over a prismatic reactor design based on the fuel and fueling system demonstrated in Germany (AVR and THTR), minimal development costs and risks because of progress in South Africa, higher capacity leading to higher performance capability, lower fuel temperatures, and a strong vendor/supplier infrastructure.

The PBMR utilizes 450,000 graphite-based spherical fuel elements, called pebbles, which are approximately 6 centimeters in diameter. These pebbles, based on the German HTR design, are located in an annular cavity in the reactor vessel. Pebbles proceed vertically downward until they are removed at the bottom. On removal they are checked, and if they are intact and not past the burnup limit, they are circulated to the input queue again. Otherwise, they are replaced with fresh pebbles. This on-line refueling feature makes refueling shutdowns unnecessary, and it also allows the reactor to operate with almost no excess reactivity, which confers advantages in safety, economy, and resistance to nuclear weapons proliferation.

The building design for a single PBMR module consists of a reinforced concrete confinement structure, called the citadel, which houses the PCU. The function of the citadel is as a confinement structure to protect the nuclear components of the power conversion unit from external missiles and to retain the vast majority of fission products that might be released in the event of a reactor accident. The limited total core power allows the reactor to be designed for passive heat conduction from the core, thermal radiation and convection from the vessel and conduction to the confinement structure, keeping temperatures low enough to prevent core or fuel damage.

The present design of the PBMR allows the use of readily available materials that have ASME Code qualification and design allowables. PBMR has concluded that these materials will not need any additional development or data base generation for use at the NGNP system design conditions.

Westinghouse recommends the use of an indirect power conversion cycle and an indirect hydrogen heat transport loop arranged in a serial fashion. The intermediate heat exchanger for the hydrogen heat transport loop would be placed first in the series in order to obtain the highest temperature gas from the nuclear reactor. After the IHX extracts $50 \mathrm{MW}$, the cooled primary loop gas would then go to the PCU. The pressure of the primary loop is $9 \mathrm{MPa}$, and the secondary loop between 8.1 and $8.5 \mathrm{MPa}$. The power conversion cycle uses steam generators and a traditional Rankine Cycle to generate electricity, and would be designed to receive the full power of the reactor.

\subsubsection{Intermediate Heat Exchanger}

WEC considered conventional shell-and-tube and compact heat exchangers. The PCHE was chosen as the preferred alternative as the shell and tube design was eliminated as not being commercially viable for a large IHX. The design tradeoffs for the PCHE were stated as: (1) More difficult inspection and maintenance, and (2) The need to establish design basis for code acceptance. 


\section{NGNP REACTOR VENDORS ADDITIONAL STUDIES (FY 2008)}

The three design teams identified in Section 1.4 performed additional analysis of the IHX and the heat transport system (HTS) in FY 2008. ${ }^{12}$ The following sections summarize their findings.

\subsection{WEC/PBMR ${ }^{13}$}

\subsubsection{Summary and Conclusions}

The Intermediate Heat Exchanger (IHX) and Heat Transport System (HTS) Conceptual Design Study has made a significant contribution to the advancement of the PBMR NGNP design. In particular, the study has provided enhanced insights into some of the more difficult issues pertaining to the HTS and its major components, especially the IHX.

The overall results of the IHX and HTS Study are summarized in the following sections, respectively addressing IHX design alternatives, IHX materials, HTS layout options and HTS technology development. Conclusions deriving from these results are given at the end of this summary, along with recommendations for further work.

\subsubsection{IHX Design Alternatives}

As requested by the BEA work statement, the assessment of IHX design alternatives began with an expansion of the initial survey of IHX alternatives that was included in Reference $1 .{ }^{1}$ In addition to the shell and tube and compact IHX options that were previously evaluated, the expanded survey included the Capillary Heat Exchanger (CHE), a small-diameter tube shell-and-tube heat exchanger proposed by UC Berkeley. The expanded survey also addressed additional attributes against which the heat exchangers were evaluated. The expanded IHX survey essentially confirmed the initial conclusions documented in the PCDSR, specifically:

- A compact heat exchanger design is required for the IHX in order to meet NGNP economic goals

- Both plate (PCHE) and plate-fin (PFHE) heat exchangers are potentially viable candidates.

It was further concluded that no incentives are seen for small-diameter tube shell-and-tube heat exchangers, relative to the compact PCHE and PFHE designs.

In parallel with the expanded assessment of design alternatives, reference IHX functions and requirements were developed as a basis for the present study. These functions and requirements were derived from those that served as the basis for the initial PCDSR design. One significant modification was made, a reversal of the normal operating pressure bias, such that the Secondary Heat Transport System (SHTS) is maintained at a slightly higher pressure than the Primary Heat Transport System (PHTS). This was done to avoid contamination of the SHTS in the event of small IHX heat transfer pressure boundary leaks. It should be noted that the modifications to the functions and requirements were developed solely for the purposes of this study, and must be confirmed for broader use through a structured conceptual design process that takes into account other factors beyond the scope of the study.

Based upon the modified functions and requirements, initial reference HTS concepts were developed for both core-side (P1) and shell-side (S3) coupling to the IHX (Figure 2-1). Since the present study was to focus on plate-fin IHX technology, core-side coupling of the PHTS was selected as the initial basis for the IHX design work to follow. This is the reverse of the PCDSR configuration, which was based upon shell-side coupling to the PHTS; however, along with the SHTS to PHTS pressure bias, it places the heat transfer cores of the IHX in compression during normal operation (potentially significant for the PFHE but not for the PCHE). Both the coupling option and the direction of pressure bias were further evaluated later in the study. 


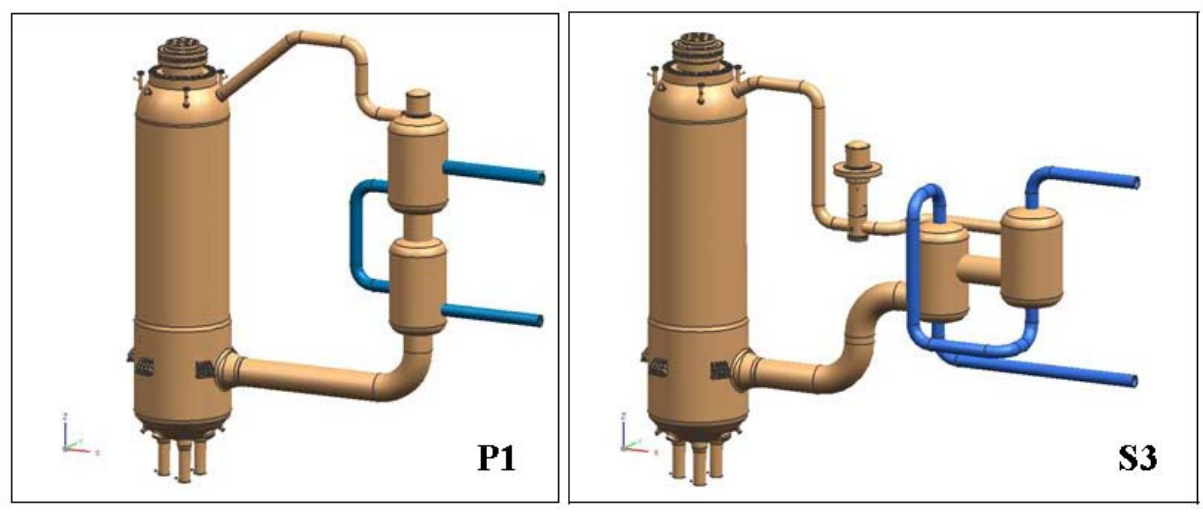

Figure 2-1. Core-side and shell-side PHTS coupling options.

Both the PFHE and PCHE are viewed as potentially viable IHX candidates. This study only focused on the PFHE. Three full-sized (510 MWt) PFHE designs were developed and evaluated for the single-loop application in response to the functions and requirements. In addition, a second small-diameter tube shell-and-tube heat exchanger, designated the "Involute Heat Exchanger," was developed and evaluated. As a result of these evaluations, Options C, one of the three PFHE designs, was selected as the basis for further work. Options $\mathrm{C}$ is shown in Figure 2-2.

A key feature of Option $\mathrm{C}$ is the individual pipes that connect the heat transfer core modules to the central ducts at the top and bottom of the heat exchanger. In addition to providing flexibility for thermal response, this feature offers the potential for module-level location and isolation of leaks across the PHTS to SHTS pressure boundary.

In addition to the $510 \mathrm{MWt}$ IHX for single-loop applications, reduced scale PFHE IHX designs were developed for two-loop $(2 \times 255 \mathrm{MWt})$ and multi-parallel $(18 \times 28.3 \mathrm{MWt})$ architectures, as input to later HTS evaluations.

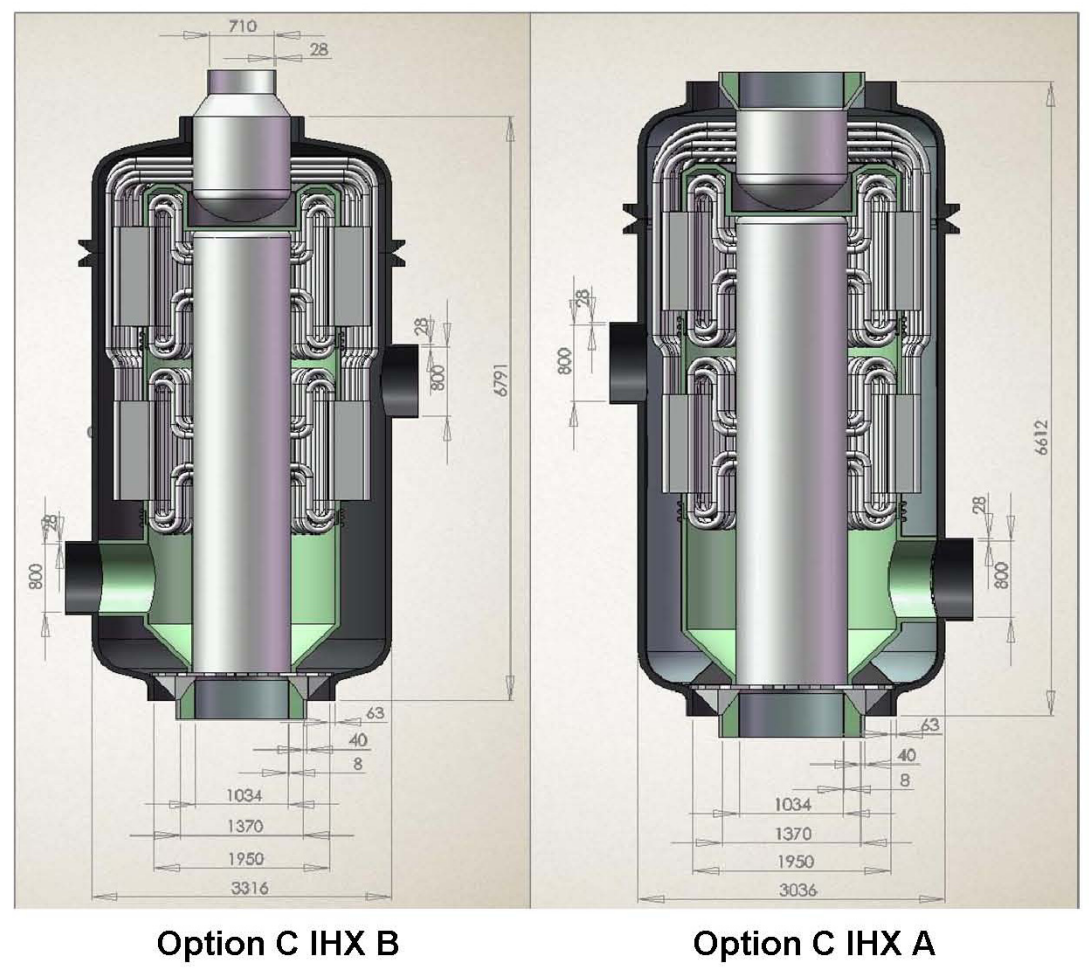

Figure 2-2. IHX Option C. 


\subsubsection{IHX Materials}

In the course of pre-conceptual design, metallic materials were identified as a key technical challenge at the specified reactor outlet temperature of $950^{\circ} \mathrm{C}$. This led to a decision to separate the IHX into two sections in series, a high-temperature section, designated IHX-A, and a lower-temperature section, designated IHX-B. During the present study, the issues pertaining to metallic materials were further addressed.

A review of the prior PCDSR materials evaluation, supplemented by an expanded survey of available data, concluded that the high-temperature characteristics of Alloy 617 are superior to those of Alloy 230 in the range of interest. It was further confirmed that the database supporting Alloy 617 is more complete. Accordingly, Alloy 617 is recommended as the basis for the high-temperature section of the IHX, IHX-A. The PCDSR selection of Alloy $800 \mathrm{H}$ was confirmed as the material selection for the lower temperature, IHX-B, section.

Materials-related lifetime limitations in the high-temperature IHX-A section were evaluated from the perspectives of both strength and environmental influences. To support this evaluation, normal operating conditions, plus two simplified transients, were specified in the functions and requirements.

The evaluation against normal operating conditions, specifically the SHTS to PHTS pressure bias at $950^{\circ} \mathrm{C}$, indicated that the lifetime of the heat transfer core matrix of the PFHE is not creep-limited, as initially expected. This was found to be true for both external (study reference with SHTS to PHTS pressure biasing and core-side coupling to the PHTS) and internal pressure biasing of the core matrix.

The first of the two evaluated transients was startup and shutdown, a high-frequency normal operating transient that involves the largest temperature change in the transition from one state to the other. The potential concern with this transient is the possibility of high-temperature low-cycle fatigue. Results of the analysis indicated that the startup/shutdown transient does not significantly influence the life of IHXA.

The second evaluated transient was loss-of-secondary-pressure (LOSP), a low-frequency design basis event (DBE). In the absence of detail system-level transients, the definition of the LOSP transient was simplified to assume an instantaneous loss of secondary pressure whilst stopping the PHTS blower. This definition is more consistent with a so-called beyond design basis event (BDBE) large pipe break. This conservative definition serves to envelope the worst case possible LOSP transient. With internal pressurization (the study reference, based on core side coupling to the PHTS), scoping analyses of the core-matrix only indicated that over 300 hours would be available prior to creep-rupture to rebalance the pressure differential across the PHTS/SHTS boundary. However, additional design and analysis will be required to confirm this result for the heat exchanger as a whole, particularly at the edges of the heat exchanger and in the manifold area. With shell-side coupling to the PHTS, the LOSP event would result in external pressure, and rupture of the pressure boundary would be unlikely.

Environmental effects, notably the potential for corrosion resulting from small levels of impurities in the high-temperature helium of the PHTS and SHTS, were a particular focus of the present study. The concern with corrosion is amplified due to the thin cross-sections associated with both the PCHE and PFHE compact heat exchangers proposed for use in the IHX application. The results of the environmental assessment suggest that corrosion effects are potentially life limiting for IHX A at $950^{\circ} \mathrm{C}$. It was further concluded that, while the indications are troubling, adequate data do not exist to assess the potential for corrosion of Alloy 617 in thin sections. Obtaining the data necessary to definitively evaluate these effects should be given high priority in the ongoing NGNP technology development program. 
Finally, it was noted that Hastelloy XR, which was used for the Japanese HTTR IHX design, has greater resistance to corrosion in the HTGR helium environment than Alloy 617; however its strength at $950^{\circ} \mathrm{C}$ is inferior. If a lower reactor outlet temperature were to be considered for the NGNP, further consideration should be given to this material.

\subsubsection{HTS Options}

In addition to the IHX, further evaluations of the circulator and steam generator, plus the need for isolation valves were undertaken as input to system-level considerations of the HTS as a whole. A particular objective of this study was to evaluate the trade-offs of one- versus two-loop HTS configurations.

\subsubsection{Circulator}

It was not possible to obtain the support of a circulator vendor due to the short timeframe allocated for the study. However, at the reactor inlet temperature selected for the PBMR NGNP $\left(350^{\circ} \mathrm{C}\right)$, the circulator design and manufacture is not viewed as being a feasibility issue. Internal assessments indicate that the circulator design will not have a significant bearing on establishing the number of HTS loops.

\subsubsection{Isolation Valves}

Functions and requirements that might lead to the selection of isolation valves in the PHTS and/or SHTS were evaluated as part of the present study. The potential sources of requirements that were considered included normal operation, including planned maintenance, investment protection and safety and licensing, including application of ASME code requirements. It was noted in the evaluation that isolation valves are already provided in the Power Conversion System (PCS) (to limit water/steam ingress into the SHTS in the event of tube failure) and in the Hydrogen Production System (HPS) to mitigate Process Coupling Heat Exchanger (PCHE) failures. Further, overpressure protection is provided in the form of relief valves in both the PHTS and SHTS.

Assuming that PHTS/SHTS pressure boundary integrity can be maintained within the IHX under LOSP conditions, no functions and requirements were identified that would indicate the need for active PHTS or SHTS isolation valves to mitigate operational events. There are potential requirements for isolation of PHTS components for maintenance purposes when the plant is shut down and the PHTS and SHTS are depressurized.

Independent of the functions and requirements assessment, summarized above, a review of the current development status of isolation valves was undertaken in response to the BEA workscope. Two examples were found of valves that have been designed and tested. The first is a $204 \mathrm{~mm}$ Japanese valve that was developed for the HTTR. The second is a $700 \mathrm{~mm}$ valve that was developed in Germany in support of the Process Nuclear Heat (PNP) plant design in the 1980s timeframe. While demonstrated temperatures are comparable, both the size and differential pressure are below those of the PBMR NGNP design. If a need were identified for such designs, both would require additional development and qualification testing. In addition to the Japanese and German valves, which are designed to be actuated in response to operational events, a third valve design was identified that is intended to support maintenance activities, while the plant is shut down at low pressure. This latter valve has undergone design only, and has not yet been fabricated or tested.

\subsubsection{Steam Generator}

An assessment of the PBMR NGNP steam generator was undertaken by Doosan Heavy Industries and Construction (DHI), an established manufacture of steam generators for the LWR industry. The assessment addressed a range of issues, including manufacturability, development needs, economics, risk, 
schedule, plus operations and maintenance. The principal focus was trade-offs between one large steam generator $(520 \mathrm{MWt})$ and two smaller parallel steam generators $(260 \mathrm{MWt})$.

The study concluded that, for the larger steam generator, there is increased, but acceptable, challenge and risk with respect to manufacturing, and that more development would be required, mainly due to the larger number of tube columns and larger diameter of the tube bundle. However, both steam generators were considered to be within the current technology base. The cost of the larger steam generator is estimated to be some $30 \%$ lower than for two of the smaller $260 \mathrm{MWt}$ steam generators. This assumes that shipping costs from the port of entry to the US site are comparable and, implicitly, that on-site assembly would not be required for either unit. No significant differences were found with respect to other factors. On balance, the lower cost of the larger steam generator is seen as outweighing the other minor differences that were noted; however, inland transportability remains to be evaluated.

\subsubsection{Options for Coupling of the IHX to the PHTS and SHTS}

With the benefit of the component-related inputs, summarized above, options for coupling the IHX to the PHTS and SHTS were further assessed in conjunction with the direction of pressure biasing during normal operation. Heat exchanger-specific differences were identified, where applicable. The most important considerations were found to include the arrangement and support of the HTS components within the Nuclear Heat Supply System building, the direction of pressure biasing during normal operation and for the LOSP event (the latter being specific to the PFHE), access for inspection and maintenance of the IHX and the related issue of the overall maintenance philosophy.

Overall, it was concluded that the scope of the present study did not provide the basis for a definitive selection of the P1 (core-side coupling to the PHTS) or S3 (shell-side coupling to the PHTS) options. As suggested above, the differences to be evaluated involve other systems, structures and components, plus plant-level assessments that were beyond the scope of the present study and more appropriate to an integrated Conceptual Design phase. In the interim, PBMR recommends the retention of IHX coupling Option P1 and SHTS to PHTS pressure biasing during normal operation as the basis for related conceptual design studies (e.g., Contamination Control).

\subsubsection{HTS Layout Evaluation}

Taking into account all of the above, a comparison was made of three HTS layout options:

- A single-loop HTS with a single 510 MWt IHX and a single $520 \mathrm{MWt}$ SG

- A two-Loop HTS with two 255 MWt IHXs and two 260 MWt SGs

- A single-Loop HTS with 18 parallel IHXs and a single 520 MWt SG.

The comparison was first undertaken from the component perspective, taking into account the perspectives of the reactor, piping, IHX, circulator, SG and PCHE. In general, a single loop configuration is preferred from the component viewpoint. However, a two-loop configuration would be also acceptable. The option of a single loop with multiple parallel-coupled IHXs was viewed as being not preferred from the piping and IHX viewpoints, due to complexity and cost.

A Kepner-Tregoe analysis was used to evaluate trade-offs from the overall system perspective, taking into account the categories of design development, manufacturing and transportability, operation and maintenance, safety and investment protection, and lifecycle cost. The Kepner-Tregoe analysis also indicated a preference for the single-loop HTS configuration. Key advantages of the single-loop HTS were related to lower capital cost and system simplicity, the latter also implying improved reliability. These advantages were seen as more than offsetting modest increases in design and development costs and risks associated with the single-loop option. 
As a conclusion of the analysis, it is recommended to remain with a single-loop HTS, with a single IHX (with A and B sections), as the reference PBMR NGNP HTS design, pending new insights from future conceptual design activities.

\subsubsection{HTS Technology Development}

With the additional insights obtained through this study, the Design Data Needs (DDNs), initially developed as part of the PBMR NGNP Preconceptual Design, were updated. Significant changes were made, primarily in the materials-related areas. Specifically, with the identification of Alloy 617 as the reference material for IHX-A, previously identified DDNs for Alloy 230 were deleted. Supplemental DDNs were identified to complete the qualification of Alloy $800 \mathrm{H}$, which was confirmed as the reference material for IHX-B. Additional DDNs were developed to address corrosion-related issues identified through the IHX materials assessment, plus issues related to diffusion bonding and brazing.

\subsubsection{WEC Conclusions}

The overall conclusions of the IHX and HTS Conceptual Design Study are summarized as follows:

1. The PCDSR recommendation to utilize PCHE or PFHE compact heat exchanger technology as the basis for the IHX design has been confirmed through the present study.

2. A compact IHX configuration (applicable to both PCHE and PFHE heat exchangers) has been identified that potentially allows leak detection, location and isolation at the module level.

3. Due to potential life limitations associated with high-temperature corrosion, the acceptability of a compact metallic IHX at $950^{\circ} \mathrm{C}$ remains to be confirmed. The present database for thin section materials is inadequate to support a definitive assessment.

4. The PCDSR recommendation to separate the IHX into IHX-A and IHX-B sections, based on temperature, is supported by the results of the present study.

5. The PCDSR recommendation to undertake a parallel development of ceramic HX technology for IHX A is confirmed by the present study.

6. The selection of core-side or shell-side coupling of the IHX to the PHTS requires additional systemand component-level information that is beyond the scope of the present study.

7. A single-loop HTS configuration is preferred, based both on component and system level considerations.

\subsubsection{WEC Recommendations}

The following recommendations are provided for future work:

1. Update the plant-level Functions \& Requirements.

It is particularly important that the NGNP mission be confirmed or redefined, along with the associated overall plant performance requirements. Especially important is the ultimate goal for the reactor outlet temperature (presently $950^{\circ} \mathrm{C}$ ). It is noted that the present PBMR NGNP Preconceptual Design offers the flexibility to initially operate as an indirect steam cycle or lower temperature process heat plant and then to evolve to higher temperatures.

2. Advance the overall NGNP Nuclear Heat Supply System (NHSS) integrated conceptual design, to better focus development of individual systems and components, including:

- Undertake a conceptual design study to develop and/or verify the combinations of insulation and active cooling provisions for the HTS. 
- A particular focus is assessing the feasibility of passive insulation for the SHTS and also it's potential for the PHTS.

- Develop HTS analytical models for the NHSS at a level sufficient to provide thermal/structural input to component designs, notably the IHX.

- Component conceptual designs (IHX, Blower, SG, PCHE etc) needed as input to HTS analytical models e.g., blower maps, mass of metal, etc. (iterative process).

- With support of the respective vendors, develop the conceptual designs of the PCHE and PFHE to a level at which structural adequacy is established for normal operation and DBEs, notably including the LOSP event. Scope to include:

- Iterative design and structural analyses

- Develop an IHX maintenance philosophy and conceptual approach for inspection and maintenance that, as a minimum, includes consideration of:

- Plant level availability and maintenance strategy/philosophy.

- The implications of leaks between the PHTS and SHTS as a function of the direction of pressure bias.

- The feasibility of heat transfer (HT) module isolation by plugging of lead-in/leadout tubes.

- Heat transfer module isolation vs. IHX replacement.

- PHTS and SHTS helium purification system requirements/capabilities.

- Further develop the IHX/HTS coupling trade-offs (P1 vs. S3 vs. other) as input to overall system-level plant layout.

- Support the development of detailed technology plans to address corrosion in thin metallic IHX sections and other high-priority DDNs (see Item 3, below).

- With the support of a vendor, develop reference circulator concepts for the PHTS and SHTS.

- With the support of a vendor, advance the reference SG design for the PCS.

- Develop a plant-level maintenance strategy/philosophy as input to component maintenance.

- Based on the above, optimize/propose a system-level layout following system-level and component design trade-offs.

- Develop first of a kind and nth of a kind cost estimates for major HTS components.

3. Develop and implement detailed technology development plans to address high-priority DDNs, notably including (in priority order):

- HTS-01-21 and HTS-01-29, Corrosion Allowances for Alloy 617 and Alloy 800H in thin sections

- As necessary, develop detailed design/specifications for a corrosion test facility

- Provide sufficient information (F\&Rs, designs, cost, schedule, etc.) to allow a decision to proceed with development of the test facility and the conduct of testing.

- HTS-01-30, Brazing and Diffusion Bonding Processes for Alloy 617 and Alloy 800H

- HTS-01-18 and HTS-01-19, Data Supporting Materials and Design Code Cases

- $\quad$ HTS-01-03 and HTS-01-24, Properties of Joints

- Complete the design and initiate the construction of a heat transfer test facility to support confirmatory IHX performance and integrity tests at the module level (HTS-01-17)

4. Establish a parallel effort to design and develop ceramic heat exchangers, as outlined in the PCDSR. 


\subsection{GA Input ${ }^{14}$}

\subsubsection{Summary}

The NGNP design concept proposed by the GA team during the NGNP preconceptual design phase comprised a single 600-MW(t) prismatic-block modular helium reactor (MHR) with two primary coolant loops for transport of the high-temperature helium exiting the reactor core to a direct Brayton cycle power conversion system (PCS) and to an intermediate heat exchanger (IHX). An integrated PCS design in which all of the PCS components are housed in a single pressure vessel was proposed to maximize cycle efficiency and therefore provide superior plant economics. The IHX was sized to transfer a nominal 65-MW(t) of heat energy to a secondary heat transport loop, which transports the heat energy to both an SI-based hydrogen production process and an HTE-based hydrogen production process. The GA team recommended that a direct combined power conversion cycle also be developed as an alternative to the integrated PCS design to reduce the programmatic risk associated with development and qualification of the integrated PCS design. The combined cycle concept included a gas turbine topping cycle combined with a conventional steam cycle. The GA Team believes that the direct Brayton cycle design concept is the best option to demonstrate highly efficient production of electricity and hydrogen, which is the primary mission of the NGNP as defined in the Energy Policy Act of 2005 (EPACT50). The GA Team further believes that the alternate direct combined cycle concept would also provide superior plant economics with respect to electricity production and is additionally attractive from the standpoint of providing the NGNP with the capability to produce steam for potential process steam applications.

Based on input from potential MHR end-users that the primary near-term interest in MHR technology is in the area of process steam/heat applications rather than in electricity and hydrogen production, the Idaho National Laboratory (INL) has imposed new requirements on the NGNP that emphasize a process steam/heat mission for the NGNP and de-emphasize the efficient electricity production mission. One of these requirements is that the NGNP PCS must be capable of producing steam. A second requirement is that the NGNP shall have an indirect power conversion cycle, which is based on the premise that an indirect cycle is more suitable to the greater emphasis on the NGNP as a nuclear heat source. These new NGNP requirements imposed by INL for conceptual design preclude the design concepts advanced by the GA Team during the preconceptual design phase. Consequently, the heat transport system configurations presented in this report represent a first-look by the GA team at indirect power conversion concepts and do not directly benefit from the work performed during the preconceptual design phase.

Given the requirement that the NGNP must have an indirect PCS (i.e., the power conversion equipment must not be in the primary coolant loop), the viability of the NGNP schedule is very much dependent on the NGNP Project's ability to procure by 2021 a suitable IHX capable of operating at a very high temperature $\left(900-950^{\circ} \mathrm{C}\right)$ in an impure helium environment. Given the extreme operating environment, the design and material options for such an IHX are limited and the IHX clearly represents a major risk for the NGNP Project. The primary focus of this study was to assess the viability of the limited IHX design and material options. The approach taken in doing this was to (1) evaluate heat transport system (HTS) configurations alternatives, (2) select two HTS alternatives and define operating conditions for these alternatives, and (3) evaluate the IHX options within the context of the selected HTS configurations. Steps 1 and 2 were necessary because, as discussed above, the NGNP configurations recommended by GA during preconceptual design features direct cycle power conversion. Step 3 included an evaluation of whether each HTS alternative would be compatible with a two-stage IHX design, with the first stage being a high-temperature replaceable module and the second stage being a lower-temperature module having an expected lifetime of 60 years. 
Based on the results of the preliminary design studies ${ }^{1}$, it is assumed that the reactor power level is $600 \mathrm{MW}(\mathrm{t})$, that $65 \mathrm{MW}(\mathrm{t})$ is transferred to the hydrogen production plants, and that the remainder of the thermal energy is transferred to the power conversion system. There are essentially two questions that need to be addressed when considering HTS alternatives for the NGNP. The first is whether the heat from the reactor should be transferred to the hydrogen plant(s) and the power conversion system in series through the same primary coolant loop(s) or through parallel primary coolant loops (to be referred to herein as the "H2 loop" and the "PCS loop"). The second question pertains to whether there should be a single or multiple PCS loops. The decision with respect to the first question is not obvious in that there are advantages and disadvantages associated with the two arrangements. Consequently GA selected one HTS configuration having a serial arrangement (Figure 4-1) and one configuration having a parallel arrangement (Figure 4-2) for detailed evaluation in this study.

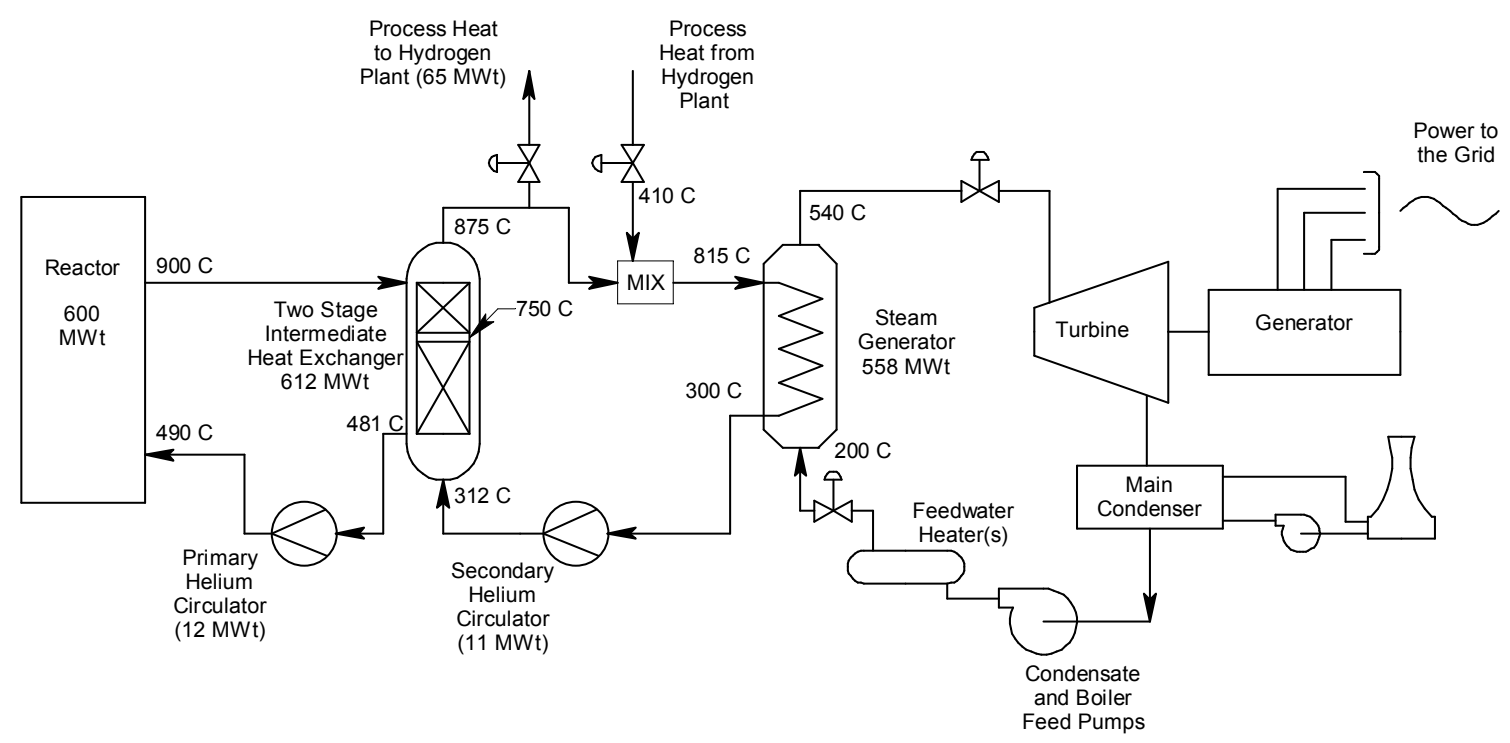

Figure 2-3. NGNP heat transport configuration - serial arrangement.

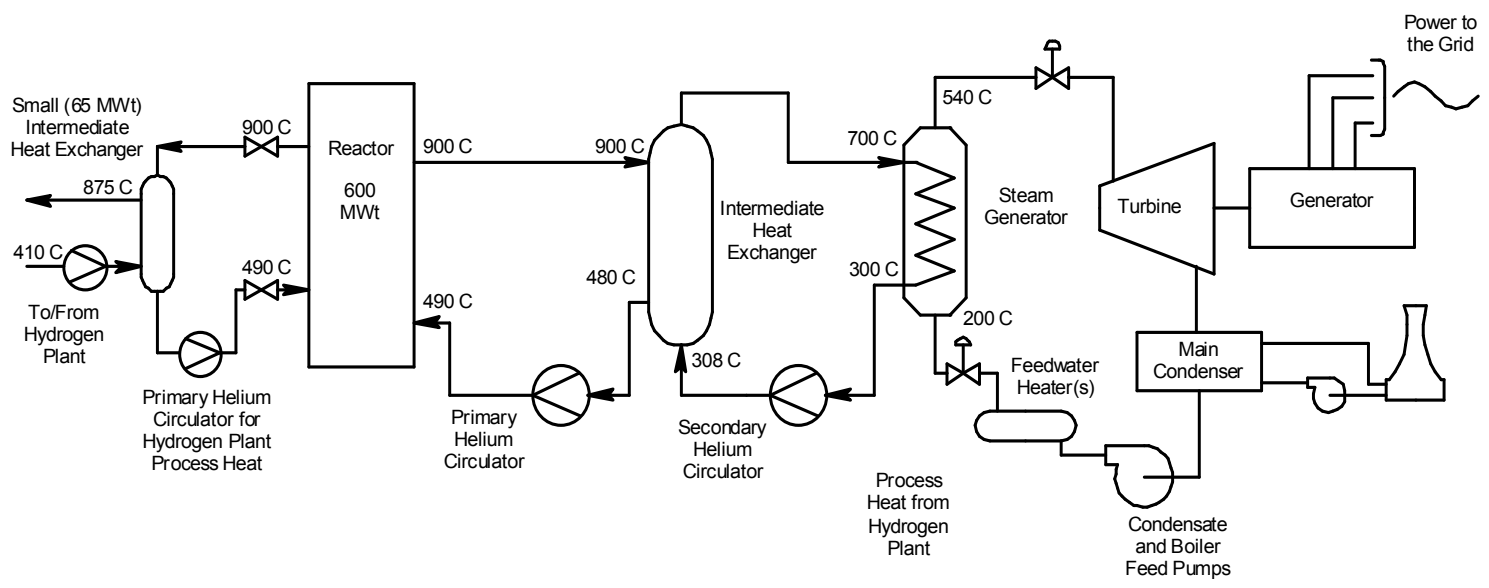

Figure 2-4. NGNP heat transport configuration - parallel primary loop arrangement. 
In accordance with the INL requirements for the NGNP, the reactor would be designed not to preclude a core outlet helium temperature of $950^{\circ} \mathrm{C}$. However, the $\mathrm{GA}$ team recommends that the reactor outlet helium temperature be limited to $900^{\circ} \mathrm{C}$, except perhaps for occasional operation at $950^{\circ} \mathrm{C}$ for the purpose of short-term, higher-temperature testing of the hydrogen production processes. This temperature is more realistic given that $950^{\circ} \mathrm{C}$ is on the fringe of the useful temperature range of the candidate materials for the IHX, and is consistent with GA's recommendations during preconceptual design. The reactor core inlet temperature would be $490^{\circ} \mathrm{C}$ when the core outlet helium temperature is either $900^{\circ} \mathrm{C}$ or $950^{\circ} \mathrm{C}$. Thus, both core-average and peak fuel temperatures would also benefit (i.e., be lower) from the lower core outlet helium temperature.

\subsubsection{Heat Transport System Alternatives}

As previously mentioned, there are advantages and disadvantages for both of the two basic heat transport configurations (e.g., serial and parallel loop). The more important of these are as noted below.

\subsubsection{Serial Configuration (Configuration 1, Figure 2-3)}

- More flexible from the standpoint of being able to vary the respective loads for the hydrogen plant (or other process heat application) and the PCS

- Better suited than the parallel loop configuration for inclusion or testing of a prototypic gas turbine PCS in the secondary loop (which Configuration 2)

- $\quad$ Less complicated and might entail lower capital costs

- Provides for a better demonstration of a full-size IHX such as would likely be used in a commercial process heat/steam plant

- Involves higher risk

- More stringent conditions for IHX, but this can be mitigated somewhat with the two-stage IHX approach

- $\quad$ More helium pumping power needed is needed - requires a larger helium circulator, which entails greater risk.

\subsubsection{Parallel Loop Configuration (Configuration 2, Figure 2-4)}

- The steam generator doesn't require a helium inlet temperature near $900^{\circ} \mathrm{C}$, so $700^{\circ} \mathrm{C}$ was specified to provide for a relatively large temperature drop across the PCS-loop IHX. The relatively large long mean temperature difference (LMTD) for the IHX greatly reduces the risk associated with the IHX

- Allows option of using proven heat exchanger technology (i.e., tube and shell type IHX)

- Less stringent conditions for compact IHX (meaning longer operating lifetime with less risk of unacceptable performance)

- Reduces capital cost

- Provides greater flexibility to test and demonstrate different process heat technologies and missions in the hydrogen loop with impacting operation of the PCS

- $\quad$ Testing of different IHX types such as ceramic heat exchangers

- Testing of different heat transport fluids in the secondary loop.

An important objective of the IHX/HTS alternatives study was to evaluate whether each HTS alternative is compatible with a two-stage IHX design, with the first stage being a relatively small high-temperature IHX that would be replaced one or more times during the lifetime of the plant and the second stage being a lower-temperature IHX having a lifetime equal to the lifetime of the plant (60 years). As noted above, a two-stage IHX would mitigate some of the risk associated with the high operating 
temperatures of the IHX in the serial configuration. Figure 2-3 shows the inlet temperature to the low-temperature IHX as being $750^{\circ} \mathrm{C}$. This temperature was selected to stay within the temperature limit for Alloy $800 \mathrm{H}$ in Section III of the ASME code. However, in sizing the high and low-temperature heat exchangers based on this temperature, it was found that the high-temperature heat exchanger would be considerably larger than the low-temperature heat exchanger, which is not consistent with the intent of the two-stage IHX approach. Raising the inlet temperature of the low-temperature IHX to $800^{\circ} \mathrm{C}$ would result in a high-temperature IHX that is smaller than the low-temperature IHX, but would also eliminate the only ASME Section III approved material option for the low-temperature IHX (although this would not necessarily preclude use of Alloy $800 \mathrm{H}$ as the material of construction).

\subsubsection{IHX Material Alternatives}

With respect to material selection for intermediate heat exchangers for indirect cycle Very High Temperature Reactors (VHTRs), this topic has been extensively studied since the early 1970's and has recently been the subject of much attention by the NGNP Project and by the Heatric Division of Meggitt LTD in the U.K. (Heatric). There is clearly a consensus that Alloy 617 and Alloy 230 are the most suitable candidates based on their having the appropriate combination of mechanical, physical, and corrosion resistant properties, with Alloy 617 having an edge primarily due to its superior creep resistance at high temperatures. Alloy XR, which was developed in Japan as an Alloy X variant with improved corrosion resistance in the VHTR environment and which was used as the material of construction for the IHX in the HTTR, would also be a candidate should the Japanese data base for this material become available to the NGNP Project or to the ASME. The NGNP Project has an ongoing materials R\&D program focused on Alloy 617 and, to a lesser extent, Alloy 230. Additionally, Heatric has an ongoing Alloy 617 development program and has already demonstrated the capability to make diffusion-bonded Alloy 617 joints that meet ASME strength requirements for the parent metal and has also fabricated a demonstration diffusion bonded Alloy 617 PCHE core with a leakage rate that meets Heatric's requirements for diffusion bonded heat exchangers.

There are, however, two potential concerns with respect to the use of Alloy 617 in VHTR heat exchangers. The first is that Alloy 617, as well as most other commercially available wrought alloys, have been found in extensive testing performed in the 1970's and 1980's to have poor resistance to corrosion in impure helium at VHTR temperatures. Specifically, the Cr-rich surface scale that forms on Alloy 617 after exposure at $800^{\circ} \mathrm{C}$ to $900^{\circ} \mathrm{C}$ in an impure helium environment was found to provide little or no protection against carbon ingress in tests performed in simulated reactor helium; consequently, the alloy experienced significant carburization in these tests. Such carburization could result in long term deterioration of the mechanical properties of the alloy during reactor service. The second concern is that Alloy 617 contains about $12.5 \%$ cobalt and that potential spallation of cobalt that becomes trapped in the surface scale that forms during high-temperature exposure to impure helium could result in Co particulates being entrained in the primary coolant. Activation of these particulates in the reactor core could result in an unacceptable circulating activity level. Indeed, these two concerns caused General Atomics to conduct an extensive high-temperature materials development program in the late 1970's and early 1980's to develop a low-cobalt alloy having improved corrosion resistance relative to Alloy 617 and other commercially available wrought alloys. Ten cobalt-free experimental alloys were developed and all of them were determined to be more carburization resistant than Alloy 617. Three of these alloys also had higher tensile properties at $900^{\circ} \mathrm{C}$ than Alloy 617. However, this development program was terminated after around 1983 and apparently none of these alloys were further developed for commercial use.

\subsubsection{IHX Alternatives}

Both helically coiled heat exchangers and compact printed circuit type heat exchangers were evaluated for the two HTS configurations shown in Figures 2-3 and 2-4. Heat transfer calculations were performed by Toshiba using the same code (HEATUP) as was used in designing the HTTR IHX. With 
respect to helical coil heat exchangers for configuration 1, it was determined that two-stage heat exchangers would be needed because of the high temperature and small LMTD and that a minimum of three sets of "hot stage IHX" and "cold stage IHX" would be needed due to manufacturing limitations. The three hot stage IHX and three cold stage IHX would have a combined heat transfer duty of $215 \mathrm{MWt}$ and $385 \mathrm{MWt}$, respectively. For configuration 2, one "small IHX" would be needed for the hydrogen loop a minimum of three "PCS-side IHX" would be needed for the PCS loop, again due to manufacturing limitations. Each PCS-side IHX has an estimated weight of about 1000 tons. The estimated weights of the other heat exchangers are of about the same magnitude.

Alloy 617 was selected as the material for the IHXs and the most severe primary stresses were calculated using ASME Section III, Division 1 - NH rules and compared with the allowable temperature and time-dependent stress intensity values for Alloy 617 developed by Oak Ridge National Laboratory (ORNL). Lifetimes for the various heat exchangers were estimated based on the calculated stresses and the allowable stress intensities. A lifetime of 60 years was estimated for the PSC-side IHX in Configuration 2 and the cold stage IHX in Configuration 1. A lifetime of 10 years was estimated for the small H2-side IHX in Configuration 2 and the hot stage IHX in Configuration 1.

The sizes and estimated lifetimes of Heatric-type compact heat exchangers (PCHE) were also calculated for Configurations 1 and 2. The conclusion was that a single hot stage and a single cold stage PCHE having heat transfer duties of $215 \mathrm{MWt}$ and $385 \mathrm{MWt}$ would be needed. Toshiba recommended that these IHX be contained in separate vessels. Configuration 2 would require a single $65 \mathrm{MWt}$ PCHE for the H2-side loop and a single $535 \mathrm{MWt}$ IHX for the PCS-side loop. The weight of each of these PCHE would be of the order of several hundred tons. A lifetime of 60 years was estimated for the cold stage IHX in Configuration 1 and a lifetime of 20 years was estimated for the hot stage IHX in Configuration 1 and both the small H2-side IHX and the PCS-side IHX in Configuration 2. However, Toshiba concluded that the lifetimes of these three PCHE could be increased from 20 years to 60 years by reducing the absolute pressure from $7 \mathrm{MPa}$ to $5 \mathrm{MPa}$.

Toshiba concluded that Configuration 2 is superior to Configuration 1 with respect to IHX lifetime and cost regardless of whether or helically coiled or compact heat exchangers are used.

\subsubsection{Helium Circulator Technology}

As a separate, but related, study within the HTS and IHX alternatives study, Rolls-Royce assessed the current state of helium circulator technology with respect to the anticipated circulator requirements for NGNP (as defined by GA). Various design options for helium circulators were examined as part of this study. It was concluded by Rolls-Royce that the technology required to produce high-temperature helium circulators is well understood and relatively easily available for circulators up to about $5 \mathrm{MWe}$. This conclusion was confirmed by a credible vendor (Howden), which indicated that they consider circulators of up to about $6 \mathrm{MWe}$ to be currently viable. This includes circulators featuring magnetic bearings.

As circulator power is increased, the required development funding, the testing requirements, and the manufacturing expenses of the circulator also increase. The relationship between cost and size will not be linear; rather development costs and risk are expected to increase rapidly as machine size approaches 10 MWe. Considering the target NGNP start-up date of 2021 and the need to achieve a TRL of at least TRL 8 by this date, it is recommended that the largest circulator power that should be considered for NGNP is about $15 \mathrm{MWe}$.

Development risks should be mitigated by implementation of an early test program that is designed to check feasible limits of circulator operation. Indeed, Howden has recommended that rather than guessing at the probability of achieving a certain machine size, a testing regime could establish the feasible size based on physical limitations of insulation and materials within a reasonable time frame (e.g., 12 months 
from start of investigation). Howden also indicated that they would contribute to a risk assessment with regards to reliability. (For example, a $10 \mathrm{MW}$ machine may be far more reliable than a $15 \mathrm{MW}$ machine even though a $15 \mathrm{MW}$ machine can be manufactured.) Furthermore, optimization of the circulator design as a whole should be the subject of a more detailed design study. An expert organization, such as a circulator vendor, should be engaged by the NGNP Project at an early date in order to develop a circulator design and a demonstration/qualification program for the design.

\subsubsection{Review of NRC Guidance and Regulations Potentially Applicable to NGNP}

As a second separate, but related, study within the IHX/HTS Alternatives Study, URS - Washington Division (URS-WD) performed a review of NRC regulations and associated regulatory guidance documents and prepared a report identifying requirements and guidance that they consider to be potentially applicable to a prismatic NGNP. Title 10 of the Code of Federal Regulations (10 CFR) is the governing set of regulations for licensing domestic nuclear reactors, including Class 103 licenses and certifications for commercial reactors. Therefore, this study is based on a systematic review of $10 \mathrm{CFR}$ criteria, to identify those of interest to the design alternatives under consideration.

The review focused on the NGNP Reactor Pressure Vessel (RPV), Cross Vessel (CV), Intermediate Heat Exchanger (IHX), and secondary Heat Transport System (HTS), and the functions performed by these Structures, Systems, and Components (SSCs). However, many of the principles and criteria are applicable to the entire NGNP design. This is critical since NRC regulations (including 10 CFR 50/52, 10 CFR 100, and 10 CFR 20) are based upon assuring the radiological protection of the general public as well as plant workers, successfully achieved by implementing the "defense-in-depth" (DID) principle.

Current NRC regulations for power reactors are focused on LWR designs. As discussed in Section 7.2, 10 CFR 50.43(e)1 must be addressed. This will be a complex undertaking, and since the NGNP is not a prototype plant, compliance against 10 CFR 50.43(e)1, as a minimum will be required. Therefore, the review also highlighted criteria and potential issues whose resolution may influence ongoing rulemaking and standards development efforts in support of NGNP licensing (e.g., risk-informed and performance based rulemaking via 10 CFR 53.

\subsection{AREVA Input ${ }^{15}$}

\subsubsection{Introduction}

This study is carried out in the context of the Next Generation Nuclear Plant (NGNP) project. It follows activities carried out in 2007 during the preconceptual design studies and is aimed at providing additional information to support the selection of key parameters and technologies for the NGNP (e.g., reactor power, gas outlet temperature, IHX design and materials, etc).

This study will characterize the advantages and disadvantages and technical risks of the potential alternatives for the intermediate heat exchangers (IHXs) to Power Conversion System (PCS) and $\mathrm{H}_{2}$ plant, secondary heat transport loop to PCS and Steam Generator Unit, including materials, design configuration, fabrication, operation, maintenance, in-service inspection, and means for periodic replacement. The study will also provide specific recommendations for the IHX design(s), primary and secondary loop configurations, SGU design and materials.

The report is split into 3 sections:

- IHX design alternatives

- Material alternatives

- Heat Transport System (HTS) configuration. 
The study also considers the impact of varying NGNP design and initial operating conditions (power level, core inlet and outlet temperatures, primary pressure) on the conclusions of the evaluations.

\subsubsection{Background and Assumptions}

The Preconceptual Design Studies Report ${ }^{1}$ was prepared based on the Combined Cycle Gas Turbine (CCGT) concept adopted by the ANTARES project. A configuration was proposed using multiple tubular IHX with the objective of providing at the same time electricity and very high temperature heat. It was however acknowledged that the steam cycle could be the best path forward for near-term deployment of HTRs.

The present study is primarily based on the indirect steam concept which differs from the conventional steam cycle concept by the addition of an Intermediate Heat Exchanger between the Nuclear Heat Source (NHS) and the Steam Generator (see Figure 2-5). The study is performed as previously assuming direct production of Helium at very high temperature $\left(900-950^{\circ} \mathrm{C}\right)$ to feed $\mathrm{H}_{2}$ production facility. The Trade Study on Primary and Secondary cycle concept, carried out in the context of the Preconceptual Design Studies, recommended IHX in parallel and this option is still considered as valid.

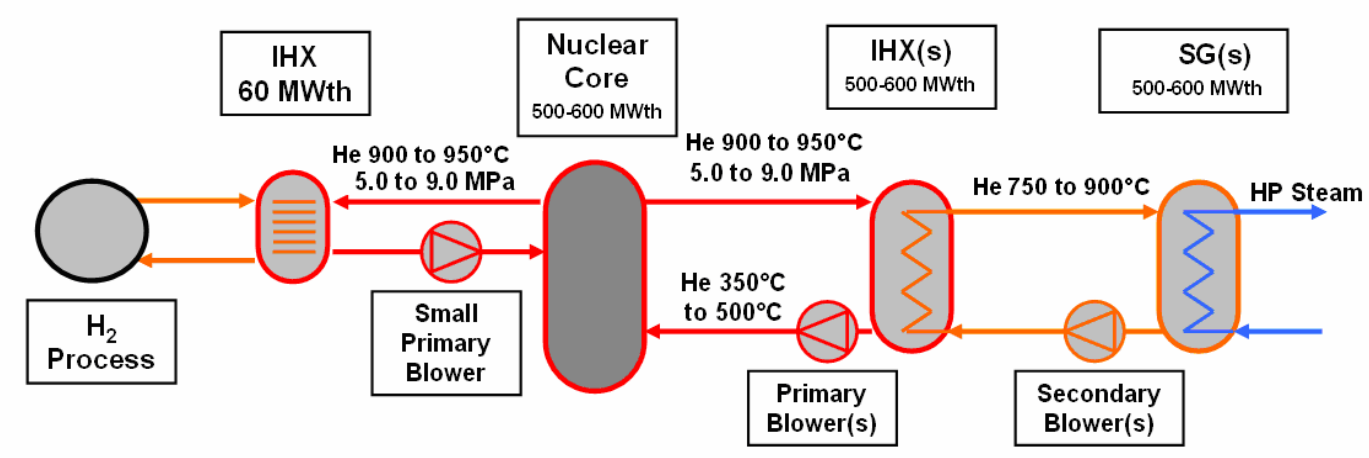

Figure 2-5. NGNP configuration considered in this study.

The main aspects of this configuration are:

- The large power loop (500-600 MWth) is dedicated to the production of High Pressure steam for electricity production. Heat is transferred from the NHS to a secondary circuit through IHX(s). In case of the use of the tubular IHX concept, a two or three loop design could be envisioned

- The intermediate circuit between the IHXs and the SGUs provides an additional confinement barrier as compared to a configuration in which the SGUs would be directly connected to the NHS. It is remarkable that in this configuration, the transients that the IHX has to withstand at secondary side are smoothed as compared to the CCGT (Combined Cycle Gas Turbine) option.

- One test scale IHX (60 MWth) is dedicated to an experimental loop including a hydrogen production unit. This loop is also seen as a way to experiment an innovative concept of IHX like a metallic plate type IHX. A reduced lifetime of 5 years of operation is considered as acceptable for this IHX due to the low availability expected for this test loop.

- Helium is used in primary and secondary circuits. This allows high thermohydraulic performances for the IHX thanks to the good coolant properties of Helium as compared to other gases. In addition, the use of Helium eliminates the nitriding problem that appears when using a Helium/Nitrogen mixture at secondary side for the CCGT option. 
One important assumption in carrying out this work and in particular the Heat Transport System configuration study is the objective of beginning initial operation of NGNP in 2021.

\subsubsection{IHX Design Alternatives}

\subsubsection{Scope of work}

This work is aimed at comparing the characteristics and development requirements for the candidate IHX designs. This comparison will include shell and tube, plate-fin, compact and other potential heat exchanger designs.

This work will be performed in two steps. The first step will identify the different concept alternatives and will provide a comparison table.

Based on this evaluation, two concepts will be selected and a comparison will be performed on the following factors:

- Current state-of-the-art and the steps necessary to extend the state-of-the-art to meet NGNP requirements

- Status and current planning for design, lab-scale, pilot-scale, and engineering-scale testing of the candidate designs

- Fabricability issues

- Operational issues

- Maintainability of modules or entire heat exchanger

- Replaceability of modules or entire heat exchanger

- Ability to detect leak or material failures and the consequence of leak or material failures during operation

- The impact of environmental effects (e.g., potential for dust clogging, accumulation, erosion and fouling, Tritium transfer)

- The identification of required in-service-inspection requirements and the impact of these requirements for each design and the practicality in meeting those requirements

- Required material strength properties

- Risks.

For the initial NGNP configuration the comparison should assume that the secondary fluid will be gaseous, (e.g., helium, helium/nitrogen). The work should also consider, however, the identification of alternative environments and will comment as to whether material compatibility issues should be expected.

This evaluation will finally evaluate as to whether each alternative would be compatible with a "two-stage" IHX design.

\subsubsection{IHX Concept Alternatives}

This study lists as extensively as possible the different concepts of IHX that could be envisioned for an application at high temperatures such as NGNP. A judgment is stated on the feasibility of each concept considering the range of operating conditions specified in Section 2.13. 


\subsubsection{Tubular IHX}

The tubular IHX concept consists of a helical coil tube bundle. Even if being a first of a kind for a large scale HTR, tubular heat exchangers are already used in conventional industries and benefits from a significant test experience in nuclear industries namely:

- Tests of a 10 MWth mock-up (He/He) in the Komponentenversuchskreislauf (Component Test Facility $[\mathrm{KVK}]$ ) facility in Germany by INTERATOM in the frame of the PNP project. This mock-up was coupled to a conventional heat source reaching outlet gas temperatures of up to $950^{\circ} \mathrm{C}$.

- Operation of a $10 \mathrm{MWth}$ IHX (He/He) by Japan Atomic Energy Research Institute (JAERI). This IHX was coupled to the HTTR nuclear reactor reaching outlet gas temperatures of $850^{\circ} \mathrm{C}$ for normal operation and up to $950^{\circ} \mathrm{C}$ for a limited duration.

The current state of the art is estimated to be around 150 MWth (with an approach temperature of around $50^{\circ} \mathrm{C}$ ) but could be extended to NGNP conditions with a 2 or 3 loop design.

Alloy 617 is the preferred candidate for this concept in order to benefit from the German experience. With this alloy it is, however, considered that a corrosion risk by impure helium exists at primary and secondary sides, due to expected operation at $900^{\circ} \mathrm{C}$ and above. Nevertheless, the tube wall (about $2 \mathrm{~mm}$ ) is the thickest as compared to the other concepts which makes this concept comparatively less sensitive to corrosion.

As regards thermomechanics, the tube bundle design is the most favorable to accommodate the thermal expansion and to spread the gradients over long lengths. But with temperatures of $900^{\circ} \mathrm{C}$ or $950^{\circ} \mathrm{C}$, the limits of the material resistance with respect to creep will have to be checked.

The tubular IHX is the most feasible concept to transfer the heat to the Power Conversion System.

\subsubsection{Metallic compact IHXs}

Plate type IHXs are seen as the most promising compact IHXs concepts. From the thermohydraulic point of view, $600 \mathrm{MWth}$ can be housed in a single pressure vessel.

Metallic plate type IHXs are used as "class 3" components in many nuclear applications but the technology and the materials are not the same as those required for applications at high temperatures. There is no commercial plate type IHX for high temperatures $\left(\geq 650^{\circ} \mathrm{C}\right.$ which requires the use of high temperature nickel base alloys) in operation today but numerous developments are carried out in the conventional industries. So, their manufacturability and their ability to withstand the pressure and thermal loads as well as the corrosion by impure Helium during a significant lifetime at high temperatures have to be demonstrated.

For NGNP, the $60 \mathrm{MWth}$ test loop is seen as a way to start operating with an innovative metallic plate IHX at low power.

Each concept consists of elementary modules disposed in a pressure vessel with an arrangement depending on the concept. Each module is composed of a stacking of plates between which the primary and secondary fluids flow in channels. The hydraulic diameter of these concepts is relatively small (the larger being $2.6 \mathrm{~mm}$ for the Plate Stamped Heat Exchanger) which enables high heat transfer coefficients.

The modules are radially arranged in the IHX pressure vessel around a central pipe which collects the hot secondary gas (hot center).

Remark: Due to the concept of using a set of elementary modules, it is not obvious that a $60 \mathrm{MWth}$ IHX is much more feasible than a $600 \mathrm{MWth}$ IHX. The simplest approach to reduce the overall power is 
to reduce the number of modules but each of them operates independently, so that the difficulties remain unchanged. On the other hand, housing a smaller IHX in the pressure vessel allows some design modifications of each module which will be investigated further.

Two candidate alloys have been selected for these concepts, namely Alloy 617 and Alloy 230.

Details about each concept are given thereafter.

\subsubsection{Plate Machined Heat Exchanger (PMHE)}

The plate type IHX PMHE concept is based on the assembling of nickel alloy plates. The plates (thickness of about $1.4 \mathrm{~mm}$ ) are provided with channels machined using high speed machining, electrochemical etching or chemical attack. The plates are then assembled using diffusion bonding to make a module. The geometry of a plate is shown in Figure 2-6.

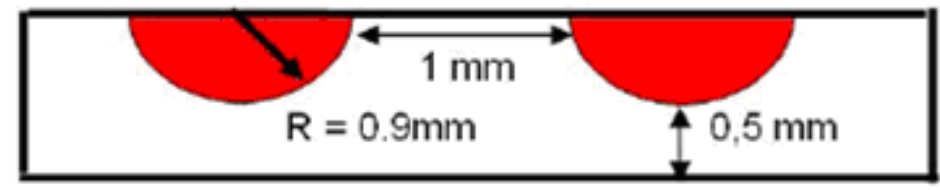

Figure 2-6. Machined plate.

Tests have shown that obtaining a satisfying geometry is difficult due to the complexity of providing the precise shape of the channels with the selected processes (mechanical, electrochemical or chemical etching). Keeping the inter channel surface plane enough for diffusion bonding is also challenging.

Besides, due to the high pressure used in the diffusion bonding phase, the shape of the channels undergo some additional deformations.

On the mechanical point of view, the stiffness provided to each module by the diffusion bonding assembly leads to high stress levels induced by thermal deformations during normal operation. Therefore, it is considered as very challenging to bring down these stresses by design improvements to values compatible with a prolonged utilization at high temperatures, even for 5 years of operations.

\subsubsection{Plate Fin Heat Exchanger (PFHE)}

Several concepts of PFHE have been studied. Both of them consist of a set of modules, each of them composed of a stacking of plane plates separated by fins that provide channels and improve the heat exchange. Several options are proposed for the fins design including wavy, straight or serrated fins. The fins are brazed on the plates for both concepts.

The fins thickness $(\leq 0.2 \mathrm{~mm})$ is regarded as a serious concern regarding corrosion by impure Helium. It is reckoned that the whole thickness of the fins would be subject to internal oxidation after a limited lifetime if no coating is applied on the material.

In addition, some difficulties have been encountered regarding brazing of the fins onto the plates.

Lastly, as well as for the PMHE concept, the stress levels calculated do not seem to be compatible with the expected lifetime and temperatures.

For these reasons, the PFHE is not seen as a promising concept for NGNP. 


\subsubsection{Plate Stamped Heat Exchanger (PSHE)}

The PSHE concept consists of a set of modules, each being composed of a stacking of plates stamped with corrugated channels. The plates are stacked in such a way to cross the channels of two consecutive plates and, therefore, to allow the different channels to communicate through the width of the plate as shown on the left below. A general view of a plate is shown in Figure 2-7.
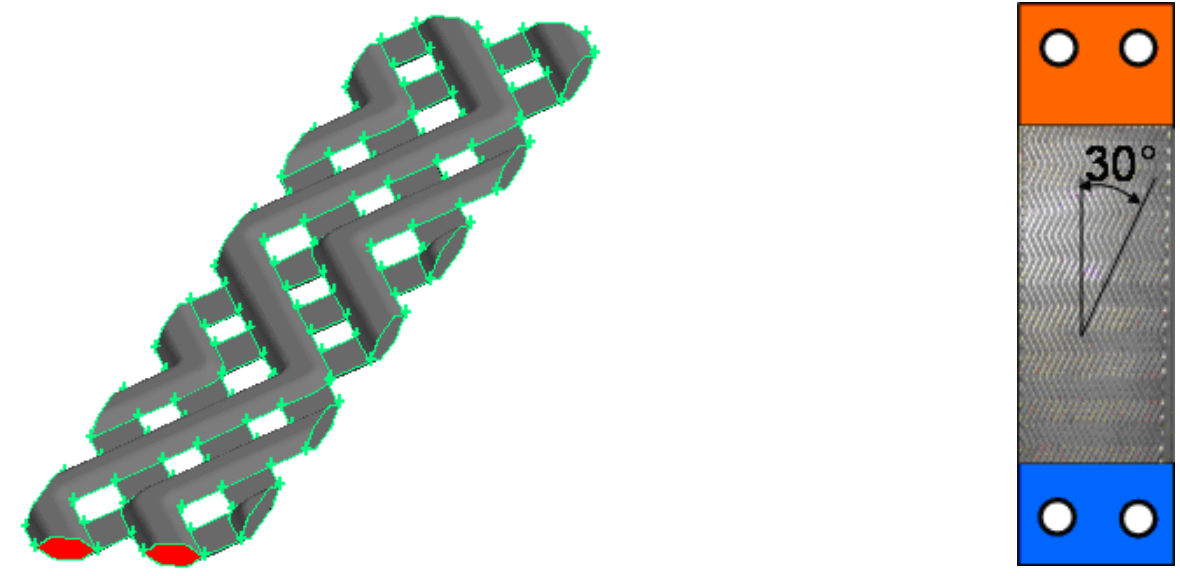

Figure 2-7. Plate stamped heat exchanger concept.

The assembly of the plates together is performed by welding on the edges of the plates only. No joint is performed in the active part of the plates, which gives to the module a relatively good flexibility. Therefore, this concept accommodates the thermal stresses better than the two other concepts of plate IHXs.

However, the stress levels with the current design are still too severe to justify even a lifetime of 5 years. Design improvements are needed and seem possible in order to reduce the thermal stresses notably.

The location of the welded joints is also favorable to inspection, even if this remains a difficult question.

The welding process which seems to be the most relevant is laser due to its capability to perform narrow-gap joints and, therefore, to avoid the overlapping of the welds of two consecutive plates. Laser welding still requires development for such an application but other processes could be envisioned if optimization of laser is not successful.

Lastly, the thickness of the PSHE plates is the largest among the metallic plate type IHX (1.5 mm) which means that it is the most favorable concept regarding material resistance to corrosion issues.

These reasons lead to consider the PSHE concept as the most promising among the plate IHXs, even if challenging design improvements are still needed.

\subsubsection{Innovative Concepts}

This part concerns some particularly innovative concepts of heat exchangers. Therefore, the technical risk linked with the important development effort requested for each of them is considered as high. 


\section{Foam IHX}

The concept is based on a stacking of plates separated by metallic foam. The barrier between the fluids is constituted by the separated plates and the fluids flow through the foam (see Figure 2-8). It is a new technology for heat exchanger application.
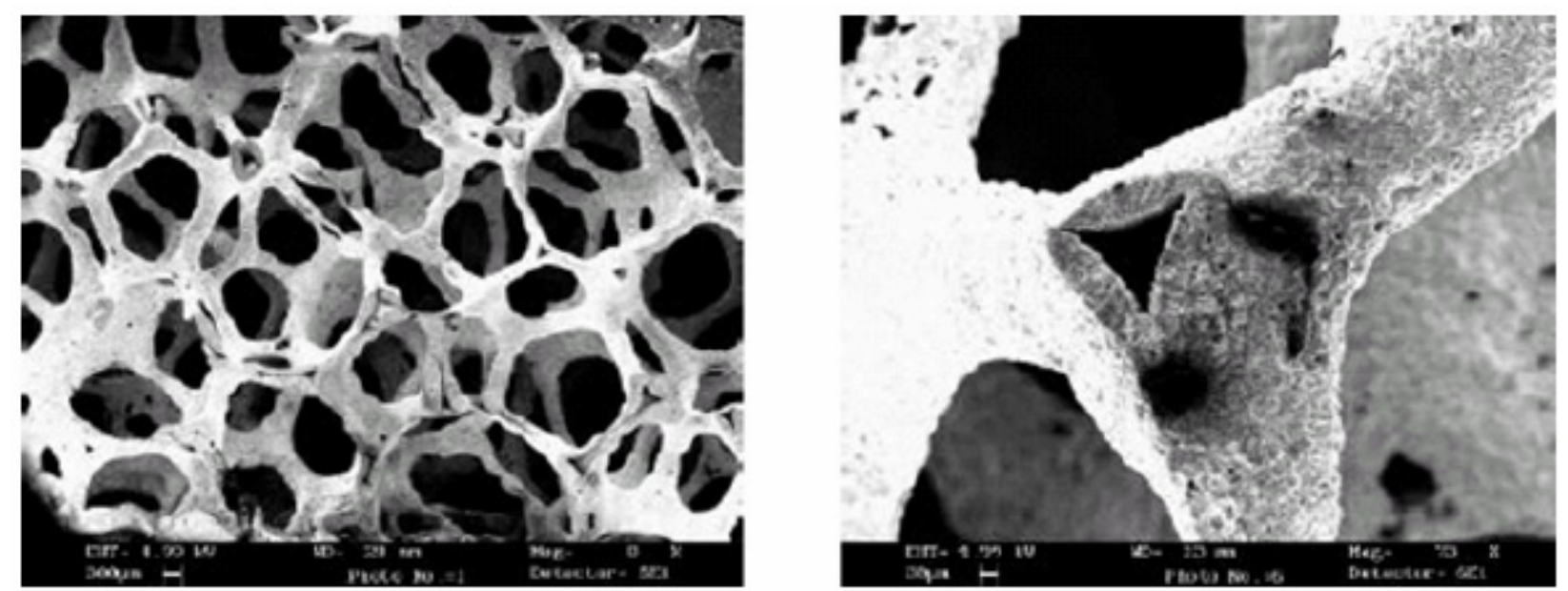

Figure 2-8. Foam concept.

Several concerns have been identified regarding this type of IHX concept:

- The pressure losses induced by the foam are particularly high.

- The loss of small fragments of the foam is hardly avoidable.

- The geometry of the foam leads to an increased risk of clogging by graphite dust.

Besides, the performance increase that was expected from the foam has not been clearly proven.

To conclude, this concept seems to present too many issues to support NGNP operation in 2021.

\section{Capillary IHX}

A "conventional" concept with thread tubes between two tube-plates with external shell including bellows has been investigated. The diameter of the tubes is of 2 to $3 \mathrm{~mm}$.

This kind of heat exchangers is currently being developed at industrial scale. The small size of the tubes allows a compactness gain but some difficulties arise at the same time:

- The vibration risk is increased so that the supporting system shall be very performing.

- The number of tubes reaches very high values, which notably increases the complexity of the manufacturing and the cost of the IHX. Notably, assembly by narrow gap welding is required.

- The technological works are mainly based on technological feasibility tests like tube to tube-plate by laser techniques. The results confirm the feasibility for limited thickness of the plate (small mock-up shown in Figure 2-9). 

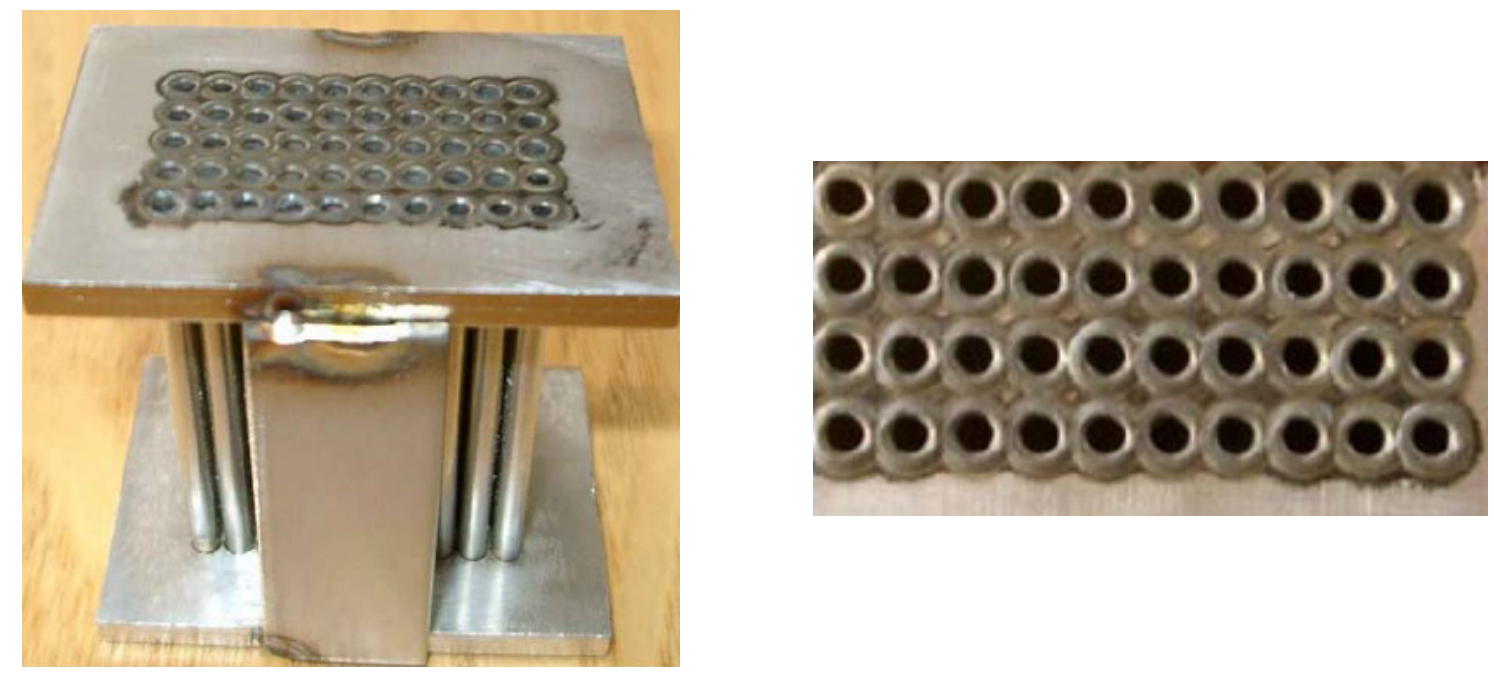

Figure 2-9. Capillary heat exchanger mock-up.

An open issue could be to adopt a new technology based on two networks of thread tubes flooded in a material, like a melted material or a powder compacted by HIP (Hot Isostatic Pressure), and the collectors are drilled.

The maturity of this concept seems too weak to support NGNP operation in 2021.

\section{Ceramic IHX}

The development of IHXs made of ceramic is still at the research stage. The UNLV (University of Nevada, Las Vegas) and the CEA notably are working on this innovative concept.

Ceramic development are either tubular or plate IHXs (mostly PFHE for the ceramic plate IHXs). Their resistance to aggressive environment is remarkable and they can operate at very high temperatures such as $1000^{\circ} \mathrm{C}$. But the fragility of ceramic makes this concept difficult to design so that it is not seen as mature enough to support NGNP operation in 2021. 


\subsubsection{Comparison of IHX Concepts}

Table 2-1 provides a high level comparison of the different IHX concept alternatives.

Table 2-1. Comparison of IHX concept alternatives.

\begin{tabular}{|c|c|c|c|c|}
\hline & Maturity & Stress behavior & $\begin{array}{l}\text { Sensitivity to } \\
\text { corrosion }\end{array}$ & Compactness \\
\hline PMHE & $\begin{array}{l}\text { Numerous } \\
\text { developments in } \\
\text { conventional industry }\end{array}$ & $\begin{array}{l}\text { High stress levels. } \\
5 \text { years lifetime seems } \\
\text { very challenging }\end{array}$ & Sensitive & $26 \mathrm{MW} / \mathrm{m}^{3}$ \\
\hline PFHE & $\begin{array}{l}\text { Numerous } \\
\text { developments in } \\
\text { conventional industry }\end{array}$ & $\begin{array}{l}\text { High stress levels. } \\
5 \text { years lifetime seems } \\
\text { very challenging }\end{array}$ & Very sensitive & $24 \mathrm{MW} / \mathrm{m}^{3}$ \\
\hline PSHE & $\begin{array}{l}\text { Numerous } \\
\text { developments in } \\
\text { conventional industry }\end{array}$ & $\begin{array}{l}\text { Challenging but best } \\
\text { stress accommodation } \\
\text { among the plate IHXs }\end{array}$ & Sensitive & $35 \mathrm{MW} / \mathrm{m}^{3}$ \\
\hline Tubular IHX & $\begin{array}{l}\text { Industrial components } \\
\text { in operation }\end{array}$ & $\begin{array}{l}\text { Limit of state of the } \\
\text { art }\end{array}$ & $\begin{array}{l}\text { Better than plates but } \\
\text { still sensitive }\end{array}$ & $0.4 \mathrm{MW} / \mathrm{m}^{3}$ \\
\hline Foam IHX & $R \& D$ & No results & $\begin{array}{l}\text { Very sensitive (loss } \\
\text { of fragments risk) }\end{array}$ & $\begin{array}{l}\text { Comparable to } \\
\text { other plate IHXs }\end{array}$ \\
\hline Capillary IHX & $\begin{array}{l}\text { Industrial } \\
\text { developments }\end{array}$ & No results & Very sensitive & $\begin{array}{l}\text { Better than } \\
\text { classical tubular } \\
\text { IHX }\end{array}$ \\
\hline Ceramic IHX & R\&D & $\begin{array}{l}\text { Difficult design } \\
\text { because of fragile } \\
\text { behavior }\end{array}$ & Resistant & $\begin{array}{l}\text { Comparable to } \\
\text { other plate IHXs }\end{array}$ \\
\hline
\end{tabular}

The tubular IHX concept is the one which is considered as the most robust and mature at the same time. Design adaptations are required to use this concept for NGNP in a 2-or 3-loop configuration but development seem to be consistent with 2021 start-up. The tubular IHX concept is recommended for the IHX to PCS.

Among the plate IHX, the PSHE concept is considered as the most promising. Therefore, this concept is recommended for the $60 \mathrm{MWth}$ test loop of NGNP. It is however underlined that some challenging design improvements are still needed for this concept to support NGNP operation by 2021.

\subsubsection{Alloy Suppliers}

\subsubsection{Introduction}

The tubular and compact IHXs will require a variety of parts made from temperature-resistant materials, including small-diameter and large-diameter tubing, plates of varying sizes and thicknesses, and a forged hemispherical head. Joining these parts will require welding materials. This section discusses the availability of the various forms of these materials and the risks in procuring them. Manufacturers of temperature-resistant materials are listed and the availability of materials in each of the required forms is discussed. In some cases, the design of the IHX may be limited by the capacity of available production facilities. 


\subsubsection{Suppliers}

To limit the required effort, the materials suppliers search was primarily focused on those in the US.

Table 2-2 lists four nickel alloys that are of interest for the IHX and six materials suppliers that provide at least one of the alloys. ASTM specifications to which materials are provided were taken from company literature. The actual products may not include all the forms listed in the ASTM specifications. For example, Special Metals produces Alloy 230 plate according to ASTM B435 but not sheet or strip.

Table 2-2. Specifications, forms, and suppliers for IHX alloys.

\begin{tabular}{|c|c|c|c|c|c|c|c|c|}
\hline Designation & 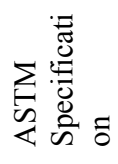 & Form & 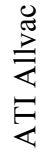 & ○ & 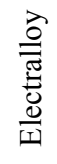 & 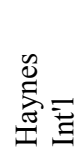 & 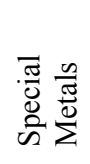 & 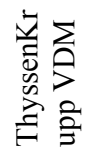 \\
\hline $\begin{array}{l}\text { UNS N06230 } \\
\text { Haynes } 230\end{array}$ & $\begin{array}{l}\text { B366 } \\
\text { B435 } \\
\text { B564 } \\
\text { B572 } \\
\text { B619 } \\
\text { B622 } \\
\text { B626 }\end{array}$ & $\begin{array}{l}\text { Wrought Fittings } \\
\text { Plate, Sheet, Strip } \\
\text { Forgings } \\
\text { Rod } \\
\text { Welded Pipe } \\
\text { Seamless Pipe, Tube } \\
\text { Welded Tube }\end{array}$ & & & & $\begin{array}{l}X \\
X \\
X \\
X \\
X \\
X \\
X\end{array}$ & $\begin{array}{l}X \\
X \\
X \\
X \\
X \\
X \\
X\end{array}$ & \\
\hline $\begin{array}{l}\text { UNS N06617 } \\
\text { Alloy } 617 \\
\text { W.Nr. } 2.4663 \\
\text { Nicrofer } 5520 \text { Co }\end{array}$ & $\begin{array}{l}\text { B166 } \\
\text { B167 } \\
\text { B168 } \\
\text { B472 } \\
\text { B546 } \\
\text { B564 }\end{array}$ & $\begin{array}{l}\text { Rod, Bar, Wire } \\
\text { Seamless Pipe, Tube } \\
\text { Plate, Sheet, Strip } \\
\text { Billets, Bars } \\
\text { Electric Fusion-Welded Pipe } \\
\text { Forgings }\end{array}$ & & & & $\begin{array}{l}X \\
X \\
X \\
X \\
X\end{array}$ & $\begin{array}{l}X \\
X \\
X \\
X\end{array}$ & $\begin{array}{l}X \\
X \\
X \\
X \\
X\end{array}$ \\
\hline $\begin{array}{l}\text { UNS N08810 } \\
\text { Alloy } 800 \mathrm{H} \\
\text { W.Nr. } 1.4876 \\
\text { W.Nr. } 1.4958 \\
\text { Nicrofer } 3220 \mathrm{H}\end{array}$ & $\begin{array}{l}\text { A240 } \\
\text { A } 480 \\
\text { B163 } \\
\text { B366 } \\
\text { B407 } \\
\text { B408 } \\
\text { B409 } \\
\text { B514 } \\
\text { B515 } \\
\text { B564 } \\
\text { B751 } \\
\text { B775 } \\
\text { B829 } \\
\text { B906 }\end{array}$ & $\begin{array}{l}\text { Plate, Sheet, Strip } \\
\text { Plate, Sheet, Strip } \\
\text { Seamless Tube } \\
\text { Wrought Fittings } \\
\text { Seamless Pipe, Tube } \\
\text { Rod, Bar } \\
\text { Plate, Sheet, Strip } \\
\text { Welded Pipe } \\
\text { Welded Tube } \\
\text { Forgings } \\
\text { Welded Tube } \\
\text { Welded Pipe } \\
\text { Seamless Pipe, Tube } \\
\text { Plate, Sheet, Strip }\end{array}$ & $\begin{array}{l}X \\
X \\
X \\
X \\
X\end{array}$ & $\mathrm{X}$ & X & & $\begin{array}{l}X \\
X \\
X \\
X \\
X \\
X \\
X \\
X \\
X \\
X \\
X \\
X \\
X \\
X\end{array}$ & $\begin{array}{l}X \\
X \\
X \\
X \\
X \\
X \\
X\end{array}$ \\
\hline $\begin{array}{l}\text { UNS N06002 } \\
\text { Alloy X } \\
\text { Alloy HX } \\
\text { W.Nr. } 2.4665 \\
\text { Nicrofer } 4722 \text { Co }\end{array}$ & $\begin{array}{l}\text { B366 } \\
\text { B435 } \\
\text { B472 } \\
\text { B572 } \\
\text { B619 } \\
\text { B622 } \\
\text { B626 } \\
\text { B751 } \\
\text { B775 } \\
\text { B829 }\end{array}$ & $\begin{array}{l}\text { Wrought Fittings } \\
\text { Plate, Sheet, Strip } \\
\text { Billets, Bars } \\
\text { Rod } \\
\text { Welded Pipe } \\
\text { Seamless Pipe, Tube } \\
\text { Welded Tube } \\
\text { Welded Tube } \\
\text { Welded Pipe } \\
\text { Seamless Pipe, Tube }\end{array}$ & $\mathrm{X}$ & $*$ & $\mathrm{X}$ & $\begin{array}{l}X \\
X \\
X \\
X \\
X \\
X \\
X\end{array}$ & $\begin{array}{l}X \\
X \\
X \\
X \\
X \\
X \\
X \\
X \\
X\end{array}$ & $\begin{array}{l}X \\
X \\
X \\
X \\
X\end{array}$ \\
\hline
\end{tabular}

*G. O. Carlson sells Alloy HX but does not mention a specification 
None of the six suppliers mentions Alloy XR or XR-II in its literature, so these alloys do not appear to be commercially available at present. Both of these are refinements on Alloy X, with generally tighter composition limits that were chosen to improve particular aspects of alloy performance. Materials manufacturers are generally able to control compositions much more closely than is required by the ASTM specifications, so unless XR and XR-II are protected by patents, it is expected that suppliers of Alloy X could also provide these alloys.

The US suppliers with the best coverage of IHX alloys are Haynes International and Special Metals, so interactions with suppliers have primarily been with these two. The discussion is generally limited to Alloys 617 and 230, which are the most promising for high-temperature IHX applications. Production of large-diameter tubing was also discussed with a forging company, Wyman-Gordon.

\subsubsection{Small-Diameter Tubing}

The current design for the tubular IHX calls for heat transfer tubing with an outside diameter of $21 \mathrm{~mm}$ and a wall thickness of $2.2 \mathrm{~mm}$. This size is similar to NPS $1 / 2 \mathrm{SCH} 10$ pipe $(21.3 \mathrm{~mm}$ outside diameter, $2.1 \mathrm{~mm}$ wall thickness). Because of the similarity in sizes, it is likely that producers of NPS $1 / 2 \mathrm{SCH} 10$ pipe could also provide tubing of the size specified for the IHX, or that the IHX could be redesigned to use NPS $1 / 2$ SCH 10 pipe. Because the IHX would require a large amount of tubing, specification of a nonstandard size is not considered to be a significant obstacle.

Tubing may be classified as either seamless or welded. Seamless tubing is produced, for example, by extrusion or by extrusion followed by various working steps such as drawing or pilgering. Seamless tubing has a uniform wrought microstructure throughout. Welded tubing is produced from strip that is formed to shape. After welding, the tubing may be cold worked. In some cases, tubing is "bead reduced," that is, worked very lightly so that only the weld bead is deformed. Because it is apt to have a nonuniform microstructure, bead reduced tubing is not recommended for use in the IHX.

In contrast to bead reduced tubing, "cold reduced" or "welded-and-drawn" tubing is worked after welding so that the entire volume of the metal is deformed. Cold reduced tubing is heat treated after the cold working step. Such tubing does not qualify as seamless, but the working and heat treating cause recrystallization of the weld zone, resulting in a microstructure that is similar to that of a wrought product.

Small-diameter welded-and-drawn tubing may be produced either in cut lengths or as a continuous coil. Cut lengths are typically limited to about $12 \mathrm{~m}$ in length. They may be acceptable, or even preferable, if the heat transfer tubing is to be butt welded, with a highly temperature-resistant alloy at the hot end of the IHX and a less temperature-resistant (and less costly) alloy at the cold end. A continuous coil is probably preferable if the entire length of a heat transfer tube is to be made from one alloy, because fewer welded joints are necessary. In either case, forming a helical heat transfer tube will involve some deformation of the tubing, so a stress relieving heat treatment is recommended.

Small-diameter tubing of Alloys 617 and 230 is a standard product and is not considered to pose significant procurement risks.

\section{Haynes International}

Haynes International currently provides both seamless and welded-and-drawn tubing of the required size in Alloy 230 only. The tubing would be provided as straight random lengths, 3 to $7.3 \mathrm{~m}$ in length. It is possible that similar tubing could be provided in Alloy 617.

The production rate is about 3050 m per month. For Alloy 617 NPS $1 / 2 \mathrm{SCH} 10$, that is about $3100 \mathrm{~kg}$ per month, so $100,000 \mathrm{~kg}$ of tubing would require about 32 months. It may also be possible to have Haynes produce strip and send it to a tube manufacturer for conversion into welded-and-drawn tubing. 


\section{Special Metals}

Special Metals produces seamless tubing of Alloy $800 \mathrm{H}$ in sizes down to NPS $3 / 4$, but it does not produce small diameter tubing of Alloys 617 or 230. Their suggested approach is to use welded-anddrawn tubing. Special Metals would produce cold-rolled strip that would be suitable for producing pipe of a size similar to NPS $3 / 4$ or 1 . The strip would be sent to a tube manufacturer, which would form the strip, autogenously weld it to form tubing, draw the tubing to the desired size, and anneal it.

One limitation to this approach is that Special Metals does not produce Alloy 230 strip, so it would not be possible to produce welded-and-drawn tubing from that alloy.

Special Metals estimates that it could produce 100,000 kg of Alloy 617 strip for tubing in about 16 weeks, with shipping to begin about 11 weeks after receipt of the order.

There are numerous tube manufacturing companies. Special Metals noted that Pressure Tube Manufacturing specializes in small diameters such as that to be used for the IHX. Conversion of strip to tubing is considered to have a short lead time.

\subsubsection{Large-Diameter Seamless Tubing}

The current design for the tubular IHX calls for the hot header to be made from a forging. Two steps are considered: production of an ingot or other suitable forging stock, and forming of the tubing. This section includes a discussion of ingot suppliers and forging.

Nickel-base alloys tend to segregate during solidification, producing variations in composition that degrade performance. Segregation would be severe if the melted alloy were simply cast in a mold. To

help control segregation and alloy composition, various advanced melting techniques are used, including vacuum arc remelting, vacuum induction melting, and electroslag remelting. These techniques are well developed and allow the production of large ingots that have closely controlled compositions throughout. Forging or other working after solidification further improves the material by refining the microstructure and reducing microscopic segregation.

Seamless tubing has been produced from nickel alloys by open-die forging and by extrusion. Both approaches are discussed here.

The experience from the KVK tests in the early 1980s is that Alloy 617 can be forged into large tubes but only with difficulty. For the KVK tests, a very large cylindrical ingot $(17,000 \mathrm{~kg})$ was upset to half its original length, forged back to its original length, then upset again. The ingot was pierced, then cooled and dressed to remove folds and tears. Finally, it was stretched and widened to its final shape. The forging was done by open-die methods, and the manufacturer apparently started by producing smaller forgings and then worked up in size. In spite of that cautious approach, "problems were encountered with widening and stretching, as the available tools, i.e., the forging mandrels were breaking due to insufficient strength. This problem was overcome by forging in the upper forging temperature range, which necessitated frequent reheating." The KVK forgings were produced by VDM.

An alternative approach, which was apparently not available at the time of the KVK work, is to form the tubing by extrusion. The process is shown schematically in Figure 2-10. A cylindrical ingot is heated to the forging temperature and then upset inside a cylindrical form or "pot." With the pot still in place, a piercing punch is pressed through the ingot. The ingot is supported by a two-piece pedestal during piercing, and the central part of the pedestal is withdrawn near the end of the piercing process. As a result, the punch can travel completely through the ingot, ejecting a plug at the end of its stroke. The hollow is then moved to a different press where a mandrel is placed through the opening, and a die is pressed down to extrude the hollow into a large-diameter tube. 


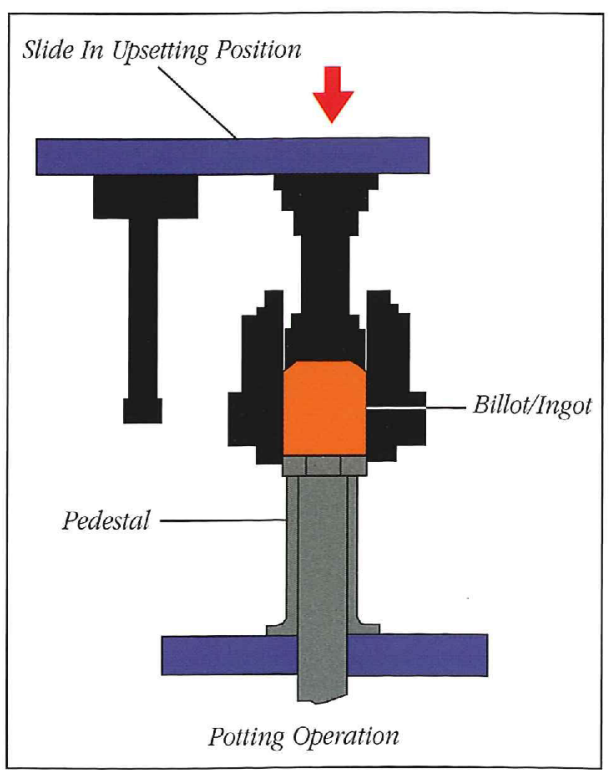

1

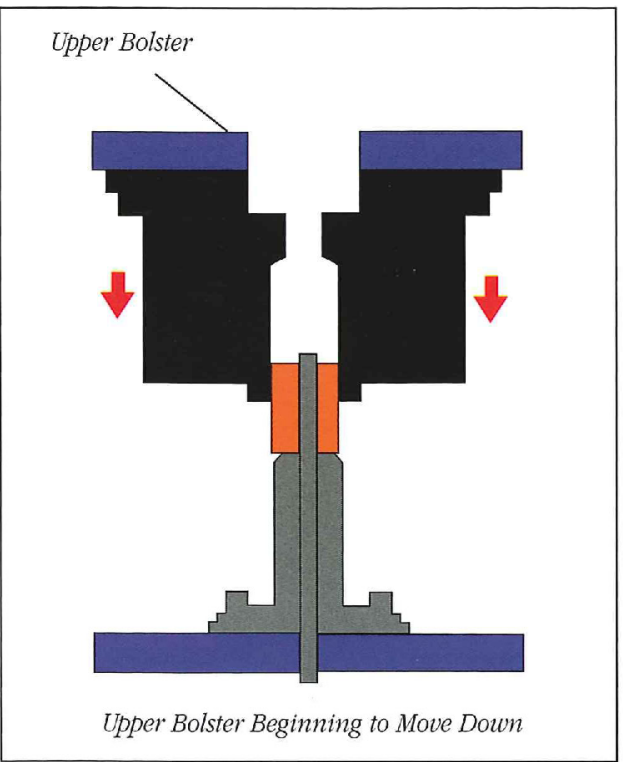

3

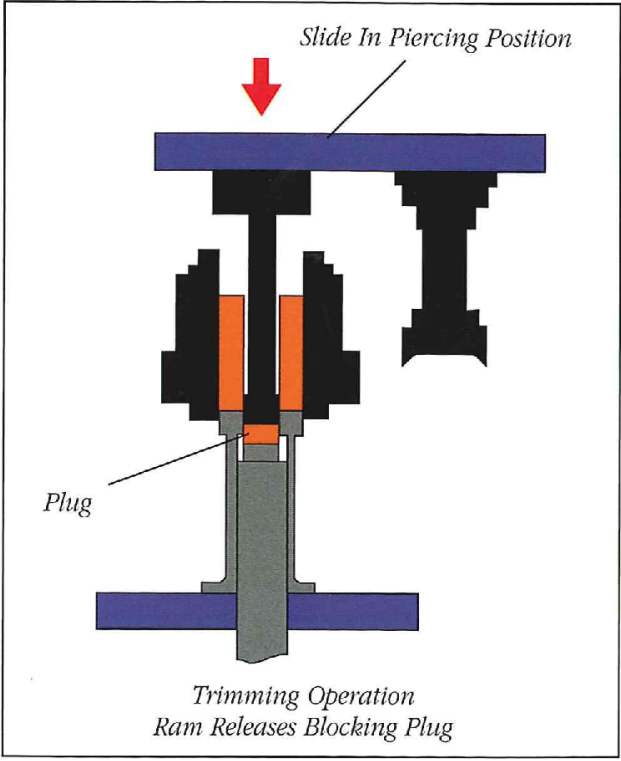

2

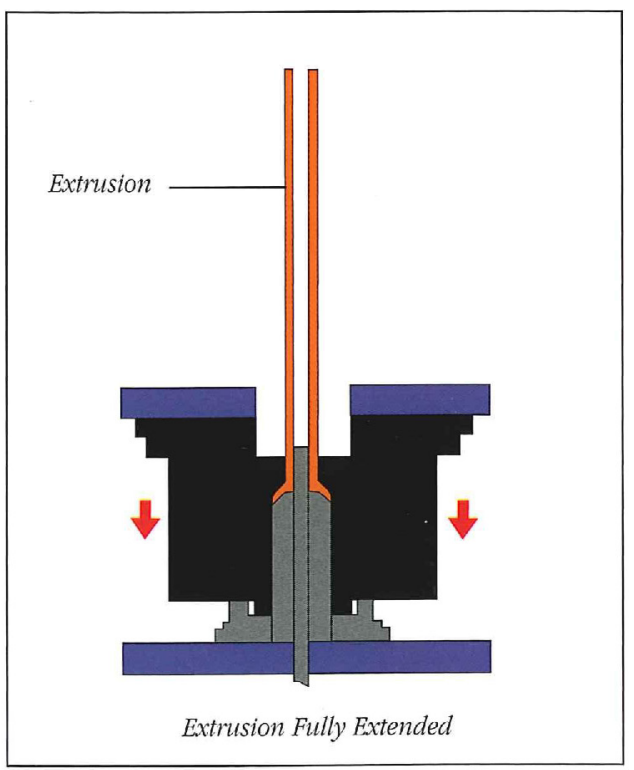

4

Figure 2-10. Tube extrusion process.

Production of large-diameter seamless tubing by extrusion is considered to be preferable to production by open-die forging, primarily because extrusion is an established process and is in regular use. In contrast, open-die forging is apparently not in regular use and requires many more steps. It is expected that a significant development effort would be needed to reestablish expertise. Only a few forging shops have the large presses required for open-die forging of tubing, and it may be difficult to find one that would be interested in such work.

The two suppliers that produce the largest seamless tubing (NPS 26 and larger) are Wyman-Gordon in the US (and Scotland) and Mannesmann in Germany. Only Wyman-Gordon was contacted for this study. 
Most of the length of the hot header will be devoted to the attachment of heat transfer tubes. Besides the tube attachment area, some additional length will be required at the ends of the header for thickness transitions and welds. The length of the tube attachment area is determined by the number of tubes to be attached, the outside diameter, and the areal density of the tubes. The KVK tests provide an indication of the areal density that can be achieved. The tubes had an outside diameter of $22 \mathrm{~mm}$, and each tube was surrounded by an annular groove with a width of $8 \mathrm{~mm}$, so the outside diameter of the annular grooves was $38 \mathrm{~mm}$. If it is assumed that the tubes were arranged in an equilateral triangular array, the tube density is about $400 \mathrm{~m}^{-2}$. If the same density can be achieved for NGNP, the hot header can be fairly short. For example, with 3000 tubes and a header with a diameter of $1100 \mathrm{~mm}$, the tube attachment area would be slightly more than $2 \mathrm{~m}$ long.

Welding the heat transfer tubes to the header is a significant challenge. Although the individual welds are relatively small and the stock is thin, there are many welds to be made, inspected, and tested, and close spacing of the tubes will require the that welding equipment fit between the tube being welded and the tubes that were welded previously. Repair of a weld after the IHX has been in service would be particularly difficult, and it may be necessary to simply plug the heat transfer tube.

There are limitations and risks related to the production of large-diameter seamless tubing. Size limitations for Wyman-Gordon are provided below; these are set by the design of the equipment and should be considered as hard limits. Within those limits, the specific dimensions to be used for the hot header must be evaluated by Wyman-Gordon to determine whether production is feasible and would result in a suitable wrought structure. There is also a risk due to lack of experience. Wyman-Gordon has worked with a variety of nickel alloys, including Alloys 600 and $800 \mathrm{H}$ but not 617 . However, they have bid on an order for Alloy 617 pipe and are working with Special Metals to produce it.

\subsubsection{Primary Metal Producer Melting Practice}

Haynes International Haynes International produces ingots of Alloys 617 and 230. The standard diameter for the ingots is $508 \mathrm{~mm}$ for Alloy 617 and $406 \mathrm{~mm}$ for Alloy 230, but larger sizes (up to 660 $\mathrm{mm}$ ) could be produced. An order of $30000 \mathrm{~kg}$ of ingots could be produced in about 13 to 14 weeks.

\section{Special Metals}

Special Metals produces ingots of Alloys 617 and 230 by either vacuum arc remelting or vacuum induction melting followed by electroslag remelting. Either process can produce ingots of over $13000 \mathrm{~kg}$, which is larger than Wyman-Gordon's preferred size (see below). The standard product is a round ingot produced by the second process with a diameter of $530 \mathrm{~mm}$. Production of $30000 \mathrm{~kg}$ of ingots is estimated to require 12 to 16 weeks from time of order.

\section{Wyman-Gordon}

Wyman-Gordon forges large-diameter seamless tubing at its plants in Houston, Texas, and Livingston, Scotland. The plant in Houston has two presses with capacities of 14,000 and 35,000 tons. The smaller of the two is used for potting (upsetting) and piercing, whereas the larger is used for extrusion. The plant in Livingston has presses of similar capacity.

There are various size limitations that need to be considered. The maximum outside diameter is limited to $1219 \mathrm{~mm}$ or possibly $1194 \mathrm{~mm}$. The minimum outside diameter is on the order of $250 \mathrm{~mm}$ and therefore should not be a significant constraint. Wall thicknesses of up to $178 \mathrm{~mm}$ have been produced . The minimum wall thickness is about $16 \mathrm{~mm}$ for smaller pipe. The maximum length that can be extruded is about $18 \mathrm{~m}$, but the maximum length that Wyman-Gordon can heat treat is about $13.5 \mathrm{~m}$. 
The maximum length is also limited by the size of the initial ingot. Wyman-Gordon prefers to limit the ingot mass to about $11000 \mathrm{~kg}$. Material loss during processing is estimated to be $10 \%$ to $15 \%$. As a point of reference, an Alloy 617 tube with an outside diameter of $1100 \mathrm{~mm}$, a wall thickness of $100 \mathrm{~mm}$, and a length of $4000 \mathrm{~mm}$ would have a mass of about $10500 \mathrm{~kg}$.

Lead time for production of pipe is currently about 30 months but the final design need not be specified until 12 months before the scheduled production date. Wyman-Gordon normally charges a 30\% penalty for contract cancellation before material is ordered, a $60 \%$ penalty for cancellation after material is ordered but before manufacturing starts, and $100 \%$ after manufacturing starts.

\subsubsection{Plates for Fabricating Large-Diameter Tubing}

The tubular and compact IHXs both include large-diameter central tubes. These may be fabricated as seamless tubing by using the methods described above. An alternative is to fabricate them from curved plates. Longitudinal welds in the hot header would be undesirable because it would probably be necessary to avoid attaching heat transfer tubes to the weld metal of the hot header, and the areas without heat transfer tubes would disrupt the symmetry of the primary gas flow. In contrast, longitudinal welds in the central tube would be substantially less disruptive and could probably be tolerated.

The central tubes will be rather long (about $12 \mathrm{~m}$ for the tubular heat exchanger), so it is probably not feasible to form a single curved plate that would run the entire length of the central tube. Instead, curved plates should be joined by longitudinal welds to form lengths of tubing, and the lengths should then be joined to form the central tube. It would not be advisable to make the circumferential welds first because it would be difficult to maintain straightness over the entire weldment.

The central tube may use different materials at different elevations, according to the service temperature at a given elevation. In that case, the effects of mismatches in thermal expansion must be considered.

The central tube for the compact heat exchanger differs from that for the tubular heat exchanger in that it will be attached to numerous heat exchanger modules, with several modules attached around the central tube at a given elevation. It is recommended that the attachments be made near the middle of a plate (or away from the ends of a length of seamless tubing), that is, away from any longitudinal or circumferential welds.

For the tubular heat exchanger, it may be desirable to have a central tube that is larger in diameter than the hot header. An increased diameter would allow space for insulation inside the central tube while maintaining an acceptably low gas speed. If the angle of taper is kept small, it would probably be acceptable to form and weld a tapered section and to weld the tapered section to the cylindrical parts. For larger angles of taper, it would be preferable to forge the curved plates so that, when welded together, there would be short cylindrical sections at the ends and a tapered section in the middle.

In general, it is expected that an increase in the diameter of the central tube would also require an increase in wall thickness. However, if the wall thickness is excessive, there is some risk that a fully wrought structure will not be achieved. Plate with a thickness of $50 \mathrm{~mm}$ or less may be considered fully wrought. Some cast (ingot) structure will remain at $75 \mathrm{~mm}$. At $100 \mathrm{~mm}$, substantial cast structure will remain, and the creep properties will differ from those of wrought material.

Within the size limitations of the mills, plate is a standard product, and there is little procurement risk.

The hot sections of the heat exchangers contain large weldments and are produced from heavy materials. There is some risk of weld cracking and welding distortion. The alloy producers describe Alloy 617 as "readily formed and welded by conventional techniques" and Alloy 230 as having "excellent 
forming and welding characteristics." It has also been stated that Alloy 230 has been welded in thicknesses up to $76 \mathrm{~mm}$, and that Alloy 617 should be easier to weld than Alloy 230. Despite such claims, it would be appropriate to consider tests to determine whether long, heavy-section welds can be made with acceptable quality and levels of distortion. The alloy suppliers provide substantial guidance on welding.

Welding distortion may cause ovality of tubing that is fabricated from curved plates, but rerounding should help to reduce the distortion.

\section{Haynes International}

Haynes International provides plate in Alloys 617 and 230 with widths up to $1828 \mathrm{~mm}$ and a maximum mass per piece of at least $2700 \mathrm{~kg}$. More massive pieces may be possible. Alloy $617 \mathrm{can}$ be produced up to $50 \mathrm{~mm}$ thick, and Alloy 230 can be produced up to $38 \mathrm{~mm}$ thick. Haynes has worked with partner companies to form plate into tubing. Production of $30000 \mathrm{~kg}$ of plate would require 22 to 28 weeks.

\section{Special Metals}

Special Metals provides plate in Alloys 617 and 230 in thicknesses up to $60 \mathrm{~mm}$ and widths up to $2438 \mathrm{~mm}$, with a maximum mass per piece of $3400 \mathrm{~kg}$. Production of $30000 \mathrm{~kg}$ of plate is estimated to require 18 weeks. If multiple shipments are desired, the first could occur 16 weeks after order.

\subsubsection{Plates for Compact IHX}

Several types of compact heat exchangers have been considered. All the designs use a stack of sheets or plates to define the flow paths for the primary and secondary gases. The material used for heat exchanger plates is sufficiently thin that alloy producers describe it as sheet rather than plate.

A plate fin heat exchanger uses a thin, corrugated foil to define the flow paths. Because of the thinness of the foil, the requirements for material performance are severe. Loss of chromium to the scale, internal oxidation, carburization, or decarburization could quickly change the chemistry of the materials and degrade their performance. For this reason, plate fin heat exchangers are not recommended.

Plate stamped and plate machined heat exchangers use more substantial plates that, as their names suggest, have stamped or machined grooves to define the flow channels. These designs are preferred because the thicker plates provide a reservoir of material that is less rapidly depleted or degraded by reactions with the primary and secondary gases.

Because of the temperature gradient from the hot end to the cold end of the heat exchanger, plates that are initially rectangular will become slightly trapezoidal during operation. A more serious design challenge is to control thermal gradients in directions perpendicular to the gas flow, which could result from variations in flow. The blocky shape of a compact heat exchanger offers little flexibility to accommodate such thermal stresses.

The edges of the plates must be reliably sealed together to avoid mixing of the primary and secondary gases. The sealing could be done by welding, brazing, or diffusion bonding. A development effort is probably needed to ensure that large compact heat exchangers can be adequately sealed and that the joints will not leak after some time in high-temperature service.

Sheet and strip of Alloys 617 and 230 are standard products and do not pose a significant procurement risk. 


\section{Haynes International}

Haynes International could produce $25000 \mathrm{~kg}$ of cold-rolled Alloy 617 or 230 sheet in about 24 to 28 weeks. The material could be supplied as coils, large flat sheets, or cut-to-size sheets. The maximum width is $1220 \mathrm{~mm}$. The maximum length of a flat sheet is $6.1 \mathrm{~m}$.

\section{Special Metals}

Special Metals could produce 25,000 kg of cold-rolled Alloy 617 sheets in about 12 weeks. The material could be supplied as coils, large flat sheets, or cut-to-size sheets. The maximum width is 1,219 $\mathrm{mm}$.

Special Metals does not produce Alloy 230 as sheet or strip.

\subsubsection{Hemispherical Head}

The design for the hot header includes a hemispherical head, which would be forged from a circular plate. It seems conservative to assume that a head of diameter $d$ could be forged from a plate of diameter $\pi d / 2$. In light of the available widths for plate $(2438 \mathrm{~mm})$, a head with a diameter of at least $1.5 \mathrm{~m}$ should be possible. That is larger than the maximum diameter for seamless tube, so the hemispherical head should not pose a size limitation.

For information on plate suppliers, see the section above on plates for large-diameter tubing. Obtaining the plate does not appear to pose a significant procurement risk.

No forging shops have been contacted, but Haynes International did not report any concerns about the feasibility of producing the head. The forging will require large dies, and manufacturing the dies may be the longest step in production.

\subsubsection{Welding Supplies}

For gas-tungsten and gas-metal arc welding, the recommended filler material for Alloy 617 is AWS A5.14 ERNiCrCoMo-1, which has the same composition as the base metal.

Haynes International recommends Alloy 230-W (AWS A5.14 ERNiCrWMo-1) for gas-tungsten and gas-metal arc welding of Alloy 230. The composition of Alloy 230-W is similar to that of Alloy 230. In contrast, Special Metals recommends either Alloy 230 or 617 as the filler for these welding processes.

The welding supplies for Alloys 617 and 230 are standard production items and do not pose a significant procurement risk.

\section{Haynes International}

Haynes International manufactures "Haynes 230-W filler wire" as its recommended filler for Alloy 230. Haynes also appears to manufacture "Haynes 617 filler wire" for Alloy 617.

\section{Special Metals}

Special Metals manufactures "Inconel Filler Metal 617" as its recommended filler for Alloy 617. It does not appear to produce a filler metal for Alloy 230.

\subsubsection{Conclusions}

Manufacturing the hot sections of the IHXs poses several challenges. Notable among these are forging the hot header, welding the many heat transfer tubes to the hot header, and assembling the central 
tube, hot header, and hemispherical head into a single weldment. Limitations of available manufacturing facilities will limit the diameter of the hot header and, if it is to be made of seamless tubing, the central tube. However, no limitations were found that would prevent construction of the IHXs. 


\section{NGNP IHX PRESSURE VESSEL AND TUBULAR IHX VENDORS}

An issue for the fabrication of the IHX pressure vessel and the tubular heat exchangers is the identification of vessel fabrication vendors with the appropriate ASME certifications to perform nuclear work. The number of these firms has declined over the last 20 years and the NGNP will be competing for these services with resurgent orders for LWR's and chemical process facility components in a world market. Table 3-1 lists the prospective vendors for this work. 
Table 3-1 IHX pressure vessel and tubular heat exchanger fabrication vendors.

\begin{tabular}{|c|c|c|c|}
\hline Vendor & Capability & QA & Nuclear Experience \\
\hline $\begin{array}{l}\text { Precision Custom } \\
\text { Components (PCC), } \\
\text { York,PA. }\end{array}$ & $\begin{array}{l}\text { The PCC facility exceeds } 25,000 \\
\text { square meters under one roof and is } \\
\text { conveniently located to major } \\
\text { transportation routes including rail, } \\
\text { truck, and deep water access in } \\
\text { Baltimore, MD and Philadelphia, PA. } \\
\text { PCC's core competency is in } \\
\text { fabrication of heavy vessels (to } 600 \\
\text { tons) involving special materials with } \\
\text { challenging welding and machining } \\
\text { requirements, tight tolerances, and } \\
\text { robust QA procedures, including } \\
\text { NQA-1. PCC has fabricated large } \\
\text { pressure vessels and other vessels and } \\
\text { equipment for the commercial nuclear } \\
\text { and process industries including } \\
\text { Westinghouse, GE, AREVA, } \\
\text { ExxonMobil, Dow, DuPont, and } \\
\text { others. } \\
\text { Facilities include large horizontal and } \\
\text { vertical boring mills, gantry mills, } \\
\text { complete automated and manual } \\
\text { welding capability and weld } \\
\text { development laboratory, heat treatment } \\
\text { facilities, } 150 \text { ton overhead cranes, } \\
\text { deep assembly and test pits, and } \\
\text { complete NDT capability in house } \\
\text { including a } 4 \text { MeV radiographic } \\
\text { inspection facility. }\end{array}$ & $\begin{array}{l}\text { The PCC Quality Assurance program is } \\
\text { routinely audited to the requirements of } \\
\text { ASME NQA-1, 10CFR50, Appendix B, } \\
\text { 10CFR71, Subpart H and 10CFR72, } \\
\text { Subpart G by various nuclear equipment } \\
\text { designers and electric utilities. PCC was } \\
\text { also audited to the ASME Code, Section } \\
\text { III, Division 1, Subsection NCA, Article } \\
4000 \text { and Section III, Division 3, Article } \\
\text { WA-4000. As a result of this audit, PCC } \\
\text { has received an "N", "NPT" and "NS" } \\
\text { Certificate of Authorizations and a "NTP" } \\
\text { Certificate of Authorization. Since 1991 } \\
\text { PCC's quality system has been audited } \\
\text { twenty-two times by utilities and } \\
\text { equipment designers and five times by the } \\
\text { Nuclear Regulatory Commission and has } \\
\text { been found to be in compliance. } \\
\text { PCC is one of only nine firms worldwide } \\
\text { who maintain ASME Section VIII } \\
\text { Division } 3 \text { certification for the design and } \\
\text { manufacture of ultra high pressure vessels. }\end{array}$ & $\begin{array}{l}\text { PCC has supplied major nuclear reactor } \\
\text { primary system components (e.g., reactor } \\
\text { heads, closure heads, and steam } \\
\text { generators), reactor service equipment, } \\
\text { fuel cycle, and related components to the } \\
\text { US Navy, NSSS providers, EPC's, and } \\
\text { electric utilities and has supplied major } \\
\text { equipment to the Department of Energy's } \\
\text { National Laboratories including Lawrence } \\
\text { Livermore Lab, Sandia Lab, Los Alamos } \\
\text { Lab, Brookhaven Lab, and Jefferson Lab. }\end{array}$ \\
\hline $\begin{array}{l}\text { ENSA (Equipos } \\
\text { Nucleares, S.A.), } \\
\text { Catabria, Spain }\end{array}$ & & $\begin{array}{l}\text { ASME “N” and other stamps since } 1978 \\
\text { AD - HPO ÜBERPRÜFUNG (TÜV) } \\
\text { ISO } 9001\end{array}$ & PBMR RPV and other components \\
\hline
\end{tabular}


Table 3-1. (continued).

\begin{tabular}{|c|c|c|c|}
\hline $\begin{array}{l}\text { GE-Hitachi Nuclear } \\
\text { Energy, Custom } \\
\text { Fabrications, } \\
\text { Canonsburg, PA }\end{array}$ & $\begin{array}{l}\text { ASME Sections III and VIII Pressure } \\
\text { vessel work has been a core business since } \\
\text { its inception. The business has maintained } \\
\text { its U certificate of authorization } \\
\text { continuously since the } 1960 \text { 's. } \\
\text { Additionally, the business has maintained } \\
\text { its N type certificates until 1986; these } \\
\text { were reestablished in } 2000 \text { and maintained } \\
\text { since. } \\
\text { The facility is equipped with all the } \\
\text { necessary welding and machining } \\
\text { capabilities and serves as a state-of-the-art } \\
\text { heavy fabrication facility. Major facility } \\
\text { highlights are as follows: } \\
30,300 \text { m }{ }^{2} \text { of Manufacturing Space Under } \\
\text { Roof (with room for expansion) } \\
\text { In-Plant Rail Spur } \\
250 \text { Ton Overhead Lifting Capacity with } 7 \\
\text { m under hook } \\
3 \text { Shift Non-Union Facility } \\
\text { CNC Five Axis Waterjet Cutting Machine } \\
\text { Vertical Milling Parts Up To } 4 \text { m In } \\
\text { Diameter and } 3.5 \text { m High } \\
\text { Horizontal Milling Parts Up To } 6 \text { m Long } \\
\text { and } 3 \text { m Wide } \\
\text { Lathes with } 1 \text { m Inch Swing and } 3 \text { m } \\
\text { Between Centers } \\
7 \text { X } 7 \text { X } 5 \text { m Assembly Pit } \\
\text { Blasting and Painting Facilities } \\
5 \text { X } 8 \text { m State-Of-The-Art X-Ray Facility } \\
\text { Rolling and Bending Capabilities } \\
\text { Full Range of Welding and Inspection } \\
\text { Equipment }\end{array}$ & $\begin{array}{l}\text { GEH has established a Quality Assurance } \\
\text { Program to assure that all fabrication and } \\
\text { construction of items and supply of } \\
\text { material are in compliance with the latest } \\
\text { requirements of the ASME Boiler and } \\
\text { Pressure Vessel Code Section III, Division } \\
1 \text { and Division 3, 10CFR50, Appendix B, } \\
\text { 10CFR71 Sub-Part H, 10CFR72 Sub-Part } \\
\text { G, 10CFR21, ASME NQA-1 (Quality } \\
\text { Assurance Requirements for Nuclear } \\
\text { Facility Applications) and contractual } \\
\text { requirements. All ASME B\&PV Code } \\
\text { work performed will be as defined in the } \\
\text { scope of our Certificates of Authorization. } \\
\text { GEH Custom Fabrication has been } \\
\text { qualified and audited by such distinguished } \\
\text { groups as the US Nuclear Regulatory } \\
\text { Commission (NRC), the American Society } \\
\text { of Mechanical Engineers (ASME), the } \\
\text { United States Department of Defense } \\
\text { (DOD), and numerous commercial } \\
\text { enterprises (Westinghouse, Bechtel, NAC } \\
\text { International, Transnuclear, Packaging } \\
\text { Technology and Fluor Hanford, etc.). }\end{array}$ & $\begin{array}{l}\text { US Nuclear Navy Nuclear Propulsion } \\
\text { system components. } \\
\text { LWR rerpalcement parts sucha s pressure } \\
\text { vessels, control rod drive mechanisms, } \\
\text { strainers, steam dryers, etc. } \\
\text { Nuclear fuel management systems such as } \\
\text { spent fuel canisters, transfer casks, wet } \\
\text { storage racks, etc. }\end{array}$ \\
\hline
\end{tabular}


Table 3-1. (continued).

\begin{tabular}{|c|c|c|c|}
\hline $\begin{array}{l}\text { Doosan Heavy } \\
\text { Industries \& } \\
\text { Construction, Seoul, } \\
\text { S. Korea }\end{array}$ & $\begin{array}{l}\text { Steel foundry with electric arc furnaces, } \\
\text { vacuum ladle refining vacuum steam } \\
\text { degassing. } \\
\text { Forge shop with } 10,000 / 13,000,4,200 \text { and } \\
1,600 \text { T presses } \\
\text { Nuclear fabrication shop } \\
\text { Heavy machine shop }\end{array}$ & ASME N, NA, NPT, U, u2, etc. & $\begin{array}{l}\text { Various Korean nuclear power plant } \\
\text { components such as: } \\
\text { Nuclear Steam Supply System at } \\
\text { Yonggwang } 1 \& 2 \text {, Ulchin } 1 \& 2 \\
\text { Design and construction of Ulchin } 3 \& 4 \\
\text { Yongggwang } 5 \& 6\end{array}$ \\
\hline $\begin{array}{l}\text { FRAMATOME } \\
\text { ANP, } \\
\text { Chalon/St. Marcel, } \\
\text { France }\end{array}$ & $\begin{array}{l}\text { Shipping on Saone River } \\
\text { Three bays, } 35,800 \mathrm{~m}^{2} \text { of shops } \\
\text { 1000T lifting capacity } \\
\text { Fully automated large welding gantries } \\
\text { Vertical lathes, boring and milling } \\
\text { machines } \\
\text { Heat treatment to } 600 \mathrm{~T} \\
\text { Steam generator fabrication capability }\end{array}$ & $\begin{array}{l}\text { ASME Section III, N, NPT } \\
\text { ISO } 9001 \\
\text { ISO } 14001 \\
\text { RCC-M per AFCEN (French Assoc. For } \\
\text { Design and Construction of Nuclear Power } \\
\text { Plant Materials) } \\
\text { French Regulations on Pressurized Water } \\
\text { Reactor (PWR), French Nuclear Steam } \\
\text { Supply System Control Office }\end{array}$ & $\begin{array}{l}600 \text { heavy components } \\
\text { Manufactured all heavy components for } \\
\text { French PWR's, (over 500) } \\
\text { Worldwide nuclear industry heavy } \\
\text { components (nearly 100) }\end{array}$ \\
\hline
\end{tabular}




\section{FACTORS INFLUENCING IHX SELECTION FOR THE NGNP}

\subsection{Material Selection}

\subsubsection{Satisfactory Microstructure}

The ASTM/ASME specifications that would be used to procure the material to fabricate the IHX (A/SA B-167, B-168, and B-564) do not list the melt practice for Alloy 617. The two prospective US material vendors use similar melting equipment for pouring the initial ingot and subsequent remelt operations of the initial ingot but will use their own melt make-up and control practices. VDM has supplied Alloy 617 material to an ORNL program and their melt practice should be verified. A problem noted for Alloy 617 is that the melt practices for a number of older heats used for mechanical properties testing could not be confirmed.

A problem of probable greater importance is the thermomechanical (forging/rolling/extrusion/heat treating) processing of the ingots into wrought product forms such as plate, strip, or tubing. The ASME specification for Alloy 617 does not contain a requirement for the grain size of the material which leaves the interpretation of the final grain size up to the manufacturer. The NGNP R\&D program should look at this issue and define a grain size requirement range for acceptability in the different product forms.

\subsubsection{In-service Track Record of Alloy}

Alloy $800 \mathrm{H}$ has been used in previous high temperature reactor programs for heat exchangers and steam generators. Alloy 617 has not been used extensively in the programs, however, it has been extensively characterized in the German and US gas reactor programs in the 1980's.

\subsubsection{Code Qualification Status}

Alloy 617 is not currently ASME Code qualified for nuclear service. The necessary R\&D to Code qualify the material for NGNP heat exchanger application is presented in detail in the NGNP IHX Technology Development Plan.

\subsection{Schedule Requirements}

\subsubsection{Material Research Needs}

The R\&D required for Code qualification and licensing is considered in detail in the NGNP IHX Technology Development Plan. Included in this plan is a detailed recommendations for development associated with welding, diffusion bonding and brazing of the metallic heat exchanger alloys. The Technology Development Plan has concluded that if sufficient resources are available the required R\&D can be accomplished to support the NGNP schedule.

Some of the issues brought up by the three contractor teams are as follows:

1. Joining of compact design (thin section) design concepts by brazing or diffusion bonding and resultant mechanical and high temperature corrosion resistance properties

2. Joining (welding) issues with helical coil designs and resultant mechanical and high temperature corrosion resistance properties

3. Development of mechanical properties to support ASME Code Case development for Alloy 617 


\subsubsection{Schedule Issues}

The availability of product forms for Alloys 617 and 230 is based on manufacturer lead times and seems to be reasonable at present. To further insure that the metallic alloy materials such as Alloy 617 for the IHX and HTS are available in a timely manner, a program to buy intermediate product forms such as slab should be investigated. This would take the alloy fabrication process through the initial melting and secondary refining steps where the product availability would not have to depend on the melt shop schedule. This intermediate product form could be stored at the supplier's facility and could be made into the final products on an as-requested basis by the component fabricators.

It would be prudent to complete the IHX design(s) so as to get the required material on order and complete the fabrication procurement. The NGNP staff should plan and execute a program of fabrication vendor interaction so as to identify qualified suppliers for development of scheduling information and final procurement. This could involve plant visits by the NGNP staff and/or a NGNP sponsored meeting where vendors could discuss the design, fabrication and schedule for manufacturing these components. 


\section{SUMMARY AND RECOMMENDATIONS}

This report addresses the acquisition strategy for the NGNP IHXT. This component will be operated in flowing, impure helium on the primary and secondary side at temperatures up to $950^{\circ} \mathrm{C}$. There are major high temperature design, materials availability, and fabrication issues that need further evaluation. The prospective materials are Alloys 617, 230, 800H and XR, with Alloy 617 being the leading candidate for the use at $950^{\circ} \mathrm{C}$. The material delivery schedule for these materials does not pose a problem for a 2021 start up as the vendors can quote reasonable delivery times at the moment. The product forms and amount needed must be finalized as soon as possible.

The proposed designs for the IHX include a plate machined heat exchanger (PMHE), plate fin heat exchanger (PFHE), and the plate stamped heat exchanger (PSHE) which are compact heat exchanger designs. The tubular IHX is a standard industrial design. Additional designs discussed in this report include the foam, capillary, and ceramic IHX designs which are less mature technologies.

An issue for the fabrication of the IHX pressure and tubular design heat exchanger is the identification of vessel fabrication vendors with the appropriate ASME certifications to perform nuclear work. The number of these firms has declined over the last 20 years and the NGNP will be competing for these services with resurgent orders for LWR's and chemical process facility components in a world market.

\subsection{Alloy}

In the pre-conceptual design studies all of the vendor teams have identified Alloy 617 as the preferred metallic material for the high temperature heat exchanger fabrication. This alloy has greater technical maturity compared to Alloy 230; it will still require successful completion of a code case for acceptance in the nuclear section of the ASME Code for this heat exchanger application.

The availability of product forms for Alloys 617 seems to be reasonable at present. To further insure that the metallic alloy materials such as Alloy 617 for the IHX and HTS are available in the proper product form in a timely manner, a program to buy intermediate product forms such as slab should be investigated. This would take the alloy fabrication process through the initial melting and secondary refining steps where the product availability would not have to depend on the melt shop schedule. This intermediate product form could be stored at the supplier's facility and could be made into the final products on an as-requested basis by the component fabricators.

It would be prudent to complete the IHX design(s) so as to get the required material on order and complete the fabrication procurement. The NGNP staff should plan and execute a program of fabrication vendor interaction so as to identify qualified suppliers for development of scheduling information and final procurement. This could involve plant visits by the NGNP staff and/or a NGNP sponsored meeting where vendors could discuss the design, fabrication and schedule for manufacturing these components. 


\subsection{IHX Design}

The important attributes of the proposed IHX designs are summarized in Table 5-1. It is clear from this summary that successful design and reasonable service life for the heat exchanger remain problematical. Tubular designs represent the configuration with minimum technical and schedule risk. These designs have a large base of service experience and are fabricated using well known fusion welding processes.

Compact designs are attractive to minimize the capital investment in materials; however, they represent a significant technical risk at this stage of their development. Qualification of diffusion bonding methods and development of in service inspection methods represent significant schedule risk.

Table 5-1. Proposed IHX design concepts.

\begin{tabular}{|c|c|c|c|c|}
\hline & Maturity & Stress behavior & $\begin{array}{l}\text { Sensitivity to } \\
\text { corrosion }\end{array}$ & Compactness \\
\hline PMHE & $\begin{array}{l}\text { Numerous } \\
\text { developments in } \\
\text { conventional industry }\end{array}$ & $\begin{array}{l}\text { High stress levels. } \\
5 \text { years lifetime seems } \\
\text { very challenging }\end{array}$ & Sensitive & $26 \mathrm{MW} / \mathrm{m}^{3}$ \\
\hline PFHE & $\begin{array}{l}\text { Numerous } \\
\text { developments in } \\
\text { conventional industry }\end{array}$ & $\begin{array}{l}\text { High stress levels. } \\
5 \text { years lifetime seems } \\
\text { very challenging }\end{array}$ & Very sensitive & $24 \mathrm{MW} / \mathrm{m}^{3}$ \\
\hline PSHE & $\begin{array}{l}\text { Numerous } \\
\text { developments in } \\
\text { conventional industry }\end{array}$ & $\begin{array}{l}\text { Challenging but best } \\
\text { stress accommodation } \\
\text { among the plate IHXs }\end{array}$ & Sensitive & $35 \mathrm{MW} / \mathrm{m}^{3}$ \\
\hline Tubular IHX & $\begin{array}{l}\text { Industrial components } \\
\text { in operation }\end{array}$ & $\begin{array}{l}\text { Limit of state of the } \\
\text { art }\end{array}$ & $\begin{array}{l}\text { Better than plates but } \\
\text { still sensitive }\end{array}$ & $0.4 \mathrm{MW} / \mathrm{m}^{3}$ \\
\hline Foam IHX & $R \& D$ & No results & $\begin{array}{l}\text { Very sensitive (loss } \\
\text { of fragments risk) }\end{array}$ & $\begin{array}{l}\text { Comparable to } \\
\text { other plate IHXs }\end{array}$ \\
\hline Capillary IHX & $\begin{array}{l}\text { Industrial } \\
\text { developments }\end{array}$ & No results & Very sensitive & $\begin{array}{l}\text { Better than } \\
\text { classical tubular } \\
\text { IHX }\end{array}$ \\
\hline Ceramic IHX & $\mathrm{R} \& \mathrm{D}$ & $\begin{array}{l}\text { Difficult design } \\
\text { because of fragile } \\
\text { behavior }\end{array}$ & Resistant & $\begin{array}{l}\text { Comparable to } \\
\text { other plate IHXs }\end{array}$ \\
\hline
\end{tabular}

\subsection{NGNP Program Forward From Here}

\subsubsection{Vendor Interactions}

The compact heat exchanger concept is being actively pursued with only one vendor (Heatric) during the pre-conceptual design phase of the project. The NGNP staff has identified another vendor (Velocys) and should visit them to determine their level of design and fabrication experience.

The NGNP staff should initiate discussions with nuclear qualified fabricators as described in Section 4.2.2. 


\section{REFERENCES}

1. INL, Next Generation Nuclear Plant Pre-Conceptual Design Report, Revision 1;

INL/EXT-07-12967; November 2007.

2. Weaver, K. D., Idaho National Laboratory, NGNP Engineering White Paper: Reactor Type Trade Study; INL/EXT-07-12729.

3. Sherman, S. R., Idaho National Laboratory, INL, NGNP Engineering White Paper: NGNP Project Pre-Conceptual Heat Transfer and Transport Studies; INL/EXT-07-12730; April 2007

4. Vandel, D. S., Idaho National Laboratory, INL, NGNP Engineering White Paper: Primary and Secondary Cycle Trade Study; INL/EXT-07-12732; April 2007.

5. Schultz, R. R., Idaho National Laboratory, INL, NGNP Engineering White Paper: Power Conversion System Trade Study; INL/EXT-07-12727; April 2007.

6. Copsey, B., Lecomte, M., Brinkmann, G., et al., "The Framatome ANP Indirect-Cycle Very High-Temperature Reactor," ICAPP 2004, Pittsburg, PA, June 13-17, 2004.

7. Proceedings of ICAPP ‘05, Seoul, Korea, May 15-19, 2005.

8. Fazluddin, S., Smit, K., Slabber, J., "The Use of Advanced Materials in VHTR's," 2nd International Topical Meeting on High Temperature Reactor Technology, Beijing, China, September 22-24, 2004.

9. Ion, S., Nicholls, D., Matzie, R., et al. "Pebble Bed Modular Reactor the First Generation IV Reactor to Be Constructed," http://www.world-nuclear.org/sym/2003/matzie.htm.

10. Matzner, D., "PBMR Project Status and the Way Ahead," Proceedings of the 2nd International Topical Meeting on High Temperature Reactor Technology, Beijing China, September 22-24, 2004, International Atomic Energy Agency: pp. 1-13.

11. Koster, A., Matzie, R., Matzner, D., "PBMR: A Generation IV High Temperature Gas Cooled Reactor," Proc. Instn Mech. Engrs, J. Power and Energy, Vol. 218, Part A.

12. WBS HTS.000.S01, "IHX and Secondary Heat Transport Loop Alternatives," dated 10-01-07.

13. S. R. Penfield, "NGNP Conceptual Design Study: IHX and Heat Transport System," NGNP-HTS-RPT-T1001, Westinghouse Electric Company, April 2008.

14. J. Bolin and J. Saurwein, 'NGNP IHX and Secondary Heat Transport Loop Alternatives Study," Report No. 911119, Revision 0, (DRAFT), April 2008.

15. B. Riou, "NGNP-IHX and Secondary Heat Transport Loop Alternatives," Document No. 12-9076325-000, (DRAFT), AREVA NP Inc., April 2008. 